\title{
Development of reconstructed intestinal micronucleus cytome (RICyt) assay in 3D human gut model for genotoxicity assessment of orally ingested substances
}

\author{
Hui Kheng Lim ${ }^{1,2,3}$ (1) Christopher Owen Hughes ${ }^{1,2} \cdot$ Michelle Jing Sin Lim ${ }^{1,4} \cdot$ Jia'En Jasmine Li $^{5} \cdot$ Moumita Rakshit $^{6}$. \\ Calvin $\mathrm{Yeo}^{5} \cdot$ Kern Rei Chng ${ }^{5}$. Angela $\mathrm{Li}^{5} \cdot$ Joanne Sheot Harn Chan ${ }^{5} \cdot \mathrm{Kee}$ Woei $\mathrm{Ng}^{6,7,8} \cdot$ David lan Leavesley ${ }^{1,2}$. \\ Benjamin Paul Chapman Smith ${ }^{1,3,4}$
}

Received: 28 September 2021 / Accepted: 12 January 2022 / Published online: 28 February 2022

(c) The Author(s) 2022

\begin{abstract}
The micronucleus (MN) assay is widely used as part of a battery of tests applied to evaluate the genotoxic potential of chemicals, including new food additives and novel food ingredients. Micronucleus assays typically utilise homogenous in vitro cell lines which poorly recapitulate the physiology, biochemistry and genomic events in the gut, the site of first contact for ingested materials. Here we have adapted and validated the MN endpoint assay protocol for use with complex 3D reconstructed intestinal microtissues; we have named this new protocol the reconstructed intestine micronucleus cytome (RICyt) assay. Our data suggest the commercial 3D microtissues replicate the physiological, biochemical and genomic responses of native human small intestine to exogenous compounds. Tissues were shown to maintain log-phase proliferation throughout the period of exposure and expressed low background MN. Analysis using the RICyt assay protocol revealed the presence of diverse cell types and nuclear anomalies (cytome) in addition to MN, indicating evidence for comprehensive DNA damage and mode(s) of cell death reported by the assay. The assay correctly identified and discriminated direct-acting clastogen, aneugen and clastogen requiring exogenous metabolic activation, and a non-genotoxic chemical. We are confident that the genotoxic response in the 3D microtissues more closely resembles the native tissues due to the inherent tissue architecture, surface area, barrier effects and tissue matrix interactions. This proof-of-concept study highlights the RICyt MN cytome assay in 3D reconstructed intestinal microtissues is a promising tool for applications in predictive toxicology.
\end{abstract}

Keywords Micronuclei $\cdot$ Reconstructed intestine micronucleus cytome (RICyt) assay $\cdot$ DNA damage $\cdot$ Mode of cell death

$\begin{array}{ll}\text { Abbreviations } \\ \text { 2D } & \text { Two dimensional } \\ \text { 3D } & \text { Three dimensional } \\ \text { BMCyt } & \text { Buccal micronucleus cytome assay } \\ \text { BN } & \text { Binucleated } \\ \text { CBMN } & \text { Cytokinesis-block micronucleus assay } \\ \text { Cyt-B } & \text { Cytochalasin B } \\ \text { DAPI } & 4^{\prime}, 6 \text {-Diamidino-2-phenylindole } \\ \text { DMEM } & \begin{array}{l}\text { Dulbecco's modification of minimal essential } \\ \text { media }\end{array} \\ \text { DMSO } & \text { Dimethyl sulphoxide } \\ \text { FITC } & \text { Fluorescein isothiocyanate } \\ \text { GI } & \text { Gastrointestinal }\end{array}$

Hui Kheng Lim

huikheng.lim@ntu.edu.sg

Extended author information available on the last page of the article

$\begin{array}{ll}\text { HBSS } & \text { Hanks balanced salt solution } \\ \mathrm{HCl} & \text { Hydrogen chloride } \\ \text { IRB } & \text { Institutional Review Board } \\ \mathrm{KCl} & \text { Potassium chloride } \\ \mathrm{MN} & \text { Micronucleus } \\ \text { OECD } & \text { Organisation for Economic Co-operation and } \\ & \text { Development } \\ \text { PD } & \text { Population doubling } \\ \text { RHE } & \text { Reconstructed human epithelial } \\ \text { RICyt } & \text { Reconstructed Intestine Micronucleus Cytome } \\ \text { RPMI } & \text { Rosewell Park Memorial Institute } \\ \text { SE } & \text { Standard error } \\ \text { SEM } & \text { Scanning electron microscopy } \\ \text { TEER } & \text { TransEpithelial Electrical Resistance }\end{array}$




\section{Introduction}

Micronuclei (MN) originate from chromosomal fragments, or individualized chromosomes, that lag behind during nuclear division (Schmid 1975; Fenech 2000; Fenech and Morley 1985a, 1985b, 1986) and are commonly used to assess the genotoxic potential of chemical reagents. In the past decade, the MN assay has become increasingly popular for identifying the hazard of acquired chromosomal damage resulting from exposure to genotoxic compounds. It has become an essential step in prioritizing compounds early in the product development process, as well as meeting regulatory and statutory requirements prior to commercialisation. OECD guidelines (487 and 474) (OECD 2014, 2016b) for the in vitro and in vivo $\mathrm{MN}$ assay have been published, to facilitate the use of MN assays for genetic toxicity testing.

Although all MN assay protocols are based on the analysis of micronuclei frequency, they vary in terms of targeted models and technical details (Sommer et al. 2020). The key criteria for any successful micronucleus assay are (1) a low reproducible MN background and (2) sufficient cell proliferation that ensures the majority of cells analysed have undergone division. One of the most widely applied in vitro methodologies is the cytokinesis-block micronucleus (CBMN) assay which halts cytokinesis by the addition of cytochalasin B (Cyt-B). The protocol is able to discriminate between dividing and non-dividing cells, thereby improving the sensitivity of the assay by excluding cells that are not capable of presenting an $\mathrm{MN}$ endpoint. This measure reduces the occurrence of confounding effects resulting from variations in cell division kinetics (Fenech 2002; KirschVolders and Fenech 2001). However, the CBMN assay is not suitable for certain studies, such as nanotoxicology, in which Cyt-B disrupts the cellular uptake of nanomaterial compounds (Zhang et al. 2016; Doak et al. 2012, 2009), as well as cells in post-DNA replication which escaped nuclear division (Bergoglio et al. 2013; Beau et al. 1998; Widrow et al. 1998). In vivo liver- and gastrointestinal tract-specific $\mathrm{MN}$ protocols have been evaluated and validated in rodents (Uno et al. 2015; Kirkland et al. 2019); tissues/animals are exposed repeatedly over a $2 / 4$-week period to ensure that sufficient cell proliferation has occurred (Hamada et al. 2015; Martus et al. 2015). However, the use of animal studies is also facing higher scrutiny nowadays with many companies and regulators moving away from in vivo testing requirements when valid non-animal alternatives exist (Boer et al. 2020; Hardy et al. 2018; Xavier et al. 2021).

As such, focus on representative in vitro tests for "site of first contact genotoxicity" is receiving more attention. Epithelial tissues represent the body's interface with the "outside world" and are the primary site of first contact for genotoxic materials. So far, there are limited epithelia-based genotoxicity models. The first is the buccal cytome MN assay which measures $\mathrm{MN}$ induced in actively dividing basal cells of oral epithelium. MN is observed in the differentiated cells of the keratinized layer at the apical buccal surface (Holland et al. 2008; Bolognesi et al. 2013). This $\mathrm{MN}$ assay protocol provides comprehensive information on the source of DNA damage, cytostasis and cytotoxicity (Sommer et al. 2020). The buccal MN assay is increasingly used in molecular epidemiological studies to investigate the impact of nutrition, lifestyle, and exposure to genotoxins and cytotoxins (Bolognesi and Fenech 2019; Fenech et al. 2011). This assay, however, is inappropriate for the safety and regulatory assessment of new and novel ingredients. The second, is the RHE-Skin MN test developed by Curren et al. (Dahl et al. 2011). This assay follows the CBMN approach, in which skin cell division is halted by Cyt-B and $\mathrm{MN}$ are scored to assess the level of genotoxicity induced by test articles. The RHE-Skin MN assay is designed for testing topically applied cosmetics or pharmaceuticals and is not suitable for food safety testing. No models currently exist for the epithelia of the gastrointestinal tract. The gut makes up a large portion of the body's external surface (Helander and Fändriks 2014) and the small intestine is where around $90 \%$ of the digestion and adsorption of food occurs (Borgstrom et al. 1957), thus it is a major exposure site of ingested genotoxicants.

Current protocols employing in vitro $2 \mathrm{D}$ intestine models to screen potential toxic effects in the gut lack the critical cell-cell interactions that occur between the outer epithelial cell layer and underlying parenchyma in vivo, and also lack the extensive and intimate interactions that occur between individual cells and their pericellular environment, the extracellular matrix. It is well described that 2D cell-based models do not adequately predict gastrointestinal toxicity (Simon-Assmann et al. 2007; Noah et al. 2011; Clevers and Batlle 2013). Attempting to overcome this, others have cultivated Caco-2 (colorectal adenocarcinoma) cells on microporous Transwell ${ }^{\mathrm{TM}}$ membranes intending to provide 3D-like architecture (Hilgers et al. 1990; Hidalgo et al. 1989; Tan et al. 2018); this approach did not evolve cryptand villus-like domains. Moreover, it is acknowledged that cancer cells (Caco-2) are not equivalent to native intestinal epithelia, rendering the value of this approach questionable. Others have used human explant tissues and laboratory animals to mimic the human small intestine. While human intestine explant cultures offer advantages over $2 \mathrm{D}$ cell cultures, the scarcity of normal donor human tissue and their short survival ex vivo are difficult to reconcile with routine experimental demands and requirement for robust reproducibility. Alternative animal models also have fundamental problems: they are expensive, have limited throughput, are often ethically challenging, and may not be representative of human physiology due to species differences. We propose 
that 3D reconstructed human epithelial (RHE) models of the intestine offer a more representative in vitro model system possessing authentic structural, biochemical, physiological, and mechanistic properties that are not available in more conventional 2D cell models of the gut. We suggest that 3D organotypic intestinal microtissues, for example EpiIntestinal $^{\mathrm{TM}}$ (MatTek Corporation ${ }^{\circledR}$ ), offer greater structural and physiological relevance, and authenticity for toxicological assessment and mechanistic research.

The 3D EpiIntestinal ${ }^{\mathrm{TM}}$ microtissues are constructed in Transwell ${ }^{\mathrm{TM}}$ devices from primary tissue obtained from consenting human donors (in accordance with MatTek Corporation IRB approval). Each microtissue construct incorporates enterocytes, Paneth cells, M cells, tuft cells, and intestinal epithelia, propagated on a basal lamina propria formed from intestinal fibroblast cells. Cultivation in vitro results in spontaneous polarized organization and differentiation, including the development of apical villus- and crypt-like domains. More than recapitulating the 3D architecture of intestinal tissue, the construct also recapitulates the biochemistry, physiology and functionality of native human small intestine in vivo (Ayehunie et al. 2018). While it has been commonly used as an in vitro model for studies of drug absorption, metabolism and inflammation in the small intestine (Ayehunie et al. 2018; Peters et al. 2019; Vaidya et al. 2019), recently the in vitro 3D-RHE intestine model has also been used to evaluate the cytotoxicity, genotoxicity and immunotoxicity of substances such as copper oxide nanoparticles (Henson et al. 2019), nanosilver (Dvorakova et al. 2015; Pind’áková et al. 2017), and food-contact materials (Bossuyt et al. 2019; Kejlova et al. 2015). The reconstructed human intestine model has been shown to exhibit physiologicallyrelevant tissue responses to xenobiotic compounds (Kejlová et al. 2019). Taken together, these data support a growing interest in the use of 3D-RHE microtissue constructs for food safety assessment.

Henceforth, we aimed to evaluate whether the MatTek 3D EpiIntestinal ${ }^{\mathrm{TM}}$ microtissue is a suitable technology platform to assess genotoxicity in the human gut. We have characterized EpiIntestinal ${ }^{\mathrm{TM}}$ microtissues and found the reconstructed human 3D EpiIntestinal ${ }^{\mathrm{TM}}$ technology platform recapitulates many characteristics of native human small intestine. To mimic in vivo exposure, we subjected EpiIntestinal $^{\mathrm{TM}}$ microtissues to prolonged exposure to reference and test compounds, using a modified MN cytome assay protocol (Ayehunie et al. 2018; Peters et al. 2019). We optimized the protocol to support the detection and analyses of chromosomal damage. Referenced scoring criteria were adopted from published protocols (Bolognesi et al. 2013, 2015, 2017; Thomas et al. 2011, 2009). We have named our new protocol the "Reconstructed Intestine Micronucleus Cytome (RICyt) assay".

\section{Materials and methods}

\section{D Tissue culture}

EpiIntestinal $^{\mathrm{TM}}$ tissue (SMI-200-FT v2.0) was purchased from MatTek Corporation ${ }^{\circledR}$ (Ashland, MA). The EpiIntestinal $^{\mathrm{TM}}$ construct is a differentiated 3D tissue model that consists of intestinal villi and crypts topology resembling the normal human small intestine. The tissue is constructed by incubating fibroblasts at $37^{\circ} \mathrm{C}$ for $4-6 \mathrm{~h}$ in cell culture inserts (surface area $=0.6 \mathrm{~cm}^{2}$, membrane pore size $=0.4 \mu \mathrm{m}$ ) and primary human small intestinal epithelial cells, derived from consented donors, were overlaid and cultured in SMI-100-MM media (MatTek Corporation ${ }^{\circledR}$ ) for 4 days submerged; and then for an additional 10 days at the air-liquid interface at $37{ }^{\circ} \mathrm{C}, 5 \% \mathrm{CO}_{2} / 95 \%$ air and 98\% relative humidity. The mature tissues are shipped sealed in 24-well agar-plugged plates to the designated laboratory (in this instance, Singapore). Upon receipt, the tissues are revived overnight in fresh SMI-100-MM before use in assays.

\section{Cell culture}

TK6 cells (CRL-8015 ${ }^{\mathrm{TM}}$, purchased American Type Culture Collection, ATCC, Manassas, VA) were cultured in RPMI1640 medium supplemented with $2 \mathrm{mM}$ L-Glutamine, $1 \mathrm{mM}$ Sodium pyruvate, $4.5 \mathrm{~g} / \mathrm{L}$ Glucose, $10 \mathrm{mM}$ HEPES, $1.5 \mathrm{~g} / \mathrm{L} \mathrm{NaHCO}_{3}$ (PAN ${ }^{\mathrm{TM}}$ Biotech, Aidenbach, Germany), $10 \%$ horse serum (Life Technologies; Thermo Fisher Scientific, Waltham, MA) and incubated at $37{ }^{\circ} \mathrm{C}, 5 \% \mathrm{CO}_{2} / 95 \%$ air and $98 \%$ relative humidity. Cells were passaged until sufficient numbers allowed for experimental purposes, counted, and seeded $\left(2 \times 10^{5}\right.$ cells/well $)$ into 12 -well plates (Falcon ${ }^{\circledR}$, Corning, Tewksbury, MA, $3.8 \mathrm{~cm}^{2} /$ well). For the non-genotoxin vs genotoxin assay, TK6 cells were seeded $\left(2 \times 10^{5}\right.$ cells/well) in 24-well plates (CELLSTAR ${ }^{\circledR}$, Grenier Bio-One, $1.9 \mathrm{~cm}^{2} /$ well). The cells were subsequently fixed in Carnoy's solution or processed via cytocentrifugation (Thermo Fisher Scientific, Waltham, MA). One thousand cells had been scored per treated sample for MN induction. The TK6 MN data were generated from independent duplicates. Each experiment consisted of a single sample per dose.

\section{Test compound preparation and treatment}

Reference genotoxins (mitomycin C, M7949, vinblastine sulphate, V1377, and benzo(a)pyrene, B1760) were purchased from Sigma Aldrich (St Louis, MO). Phenformin $\mathrm{HCl}$ (PHR1573, Supelco), purchased from Sigma Aldrich (St Louis, MO) was used as non-genotoxic negative control. 
Test compound stock solutions were prepared in DMSO (D161802, Sigma Aldrich, St Louis, MO). For the 3D tissues, dilutions were made in complete culture media yielding $\leq 0.1 \%$ DMSO final concentration. Media containing $0.1 \%$ DMSO (i.e. without test article) were applied to tissues to serve as the vehicle control. All 3D tissues were treated apically every alternate day (from day 0-6) and daily (from day 7-9), while basolateral wells contain untreated culture media to support the tissue growth. TK6 cells were exposed for $24 \mathrm{~h}$ with the test materials prior to harvest. S9 liver fraction (11-402L, MolTox, Boone, NC) was added to TK6 cells $3 \mathrm{~h}$ prior to benzo(a)pyrene exposure to activate cellular metabolism (Cox et al. 2016).

\section{Tissue dissociation}

3D tissues were dissociated using human tumour dissociation kit (Miltenyl Biotec, Bergisch Gladbach, Germany), as per manufacturers' instruction, with minor modifications. Individual 3D tissues cultured on microporous membranes were excised from the culture inserts and incubated for 15 min in cell recovery solution (Corning, Tewksbury, MA). The tissues were subsequently peeled off from the membrane with fine point forceps under stereo microscope (Leica Microsystems, Wetzlar, Germany). The peeled tissues were placed into gentleMACS C-tube (Miltenyi Biotech, Bergisch Gladbach, Germany) containing the enzyme mix described in the kit's protocol. The tubes were then transferred into a gentleMACS octo dissociator with heater (Miltenyi Biotech, Bergisch Gladbach, Germany), and subjected to one cycle of '37C_m_LPDK_1' program. Upon completion, the cell suspension was centrifuged at $1000 \mathrm{rpm}$ for $5 \mathrm{~min}$; the supernatant was removed and the pellet was resuspended in $2 \mathrm{~mL}$ of Hanks Balanced Salts Solution (HBSS). Total cell number was estimated through trypan blue dye exclusion method (Strober 2015) to determine the cell viability. The proliferation of the 3D tissue was estimated through calculation of population doubling based on the dissociated cell number at the day 1, 6 and 11 after tissue revival. The cells were then (1) fixed for micronuclei scoring or (2) processed for subsequent experimentation.

\section{Cytokinesis-blocked micronucleus analysis (CBMN)}

The CBMN assay was conducted according to a previously published procedure (Fenech and Morley 1985b). Briefly, cytochalasin B (5474, Tocris Bioscience, Bristol, UK, $6 \mu \mathrm{g} /$ $\mathrm{ml}$ ) was applied to the 3D EpiIntestinal ${ }^{\mathrm{TM}}$ in vitro tissues every other day, to the apical and to the basolateral compartments. Tissues were dissociated into single cell suspension (described above), processed with mild hypotonic cold $75 \mathrm{mM} \mathrm{KCl}$, followed by 3 fixation steps in Carnoy's fixative (methanol/acetic acid, 16:1), supplemented with formaldehyde at 1st fixation. The cell suspension was stored in fixative at $4{ }^{\circ} \mathrm{C}$ overnight, stained with acridine orange (1:100 dilution in $1 \times$ PBS, A1301, Invitrogen; Thermo Fisher Scientific, Waltham, MA) and scored under fluorescence microscopy (Zeiss Axioimager, equipped with triple band excitation fluorescence filter set: DAPI, FITC and Texas red). Scoring was performed following the criteria developed by Fenech et al. (Fenech et al. 2003, 2007). One thousand total cells per microtissue were scored to determine the percentage of cells with one (mononucleated) or two nuclei (binucleated). The results were generated from three independent experiments. Each experiment consisted of a single microtissue per dose.

\section{Micronucleus cytome assay}

Tissues were exposed to test substances, harvested and dissociated into single cell suspension as described above. Cell suspension samples were divided equally; half of the cell suspension sample was fixed in Carnoy's solution with 3 fixation steps in methanol/acetic acid 16:1, supplemented with formaldehyde at 1 st fixation. The cell suspension was aged at least overnight at $4{ }^{\circ} \mathrm{C}$ to improve the quality of fixed cells. The remaining cells were incubated with $4 \%$ formaldehyde for $15 \mathrm{~min}$, rinsed twice with $1 \times \mathrm{PBS}$ and stored in $4{ }^{\circ} \mathrm{C}$. The Carnoy-fixed cells were stained with acridine orange immediately scored per criteria originally described by Tolbert et al. (Tolbert et al. 1992) and Thomas et al. (Thomas et al. 2009). Formaldehyde-fixed cells were stained with either DAPI alone (test compound treated) or DAPI and active caspases-3 antibody (9661S, Cell Signalling Technology, Danvers, MA) (DMSO treated). Fluorescence microscopy was used to capture images of untreated/treated sample; high-resolution images were analysed using ImageJ software (Rasband, W.S., ImageJ, U. S. National Institutes of Health, Bethesda, Maryland, USA, https://imagej.nih.gov/ ij/, 1997-2018). One thousand total cells were scored per microtissue to determine the frequency of $\mathrm{MN}$ and cytome. The percentage of $\mathrm{MN}$ and cytome at each concentration of test chemical was compared with the solvent control. The results were generated from three independent experiments. Each experiment consisted of a single microtissue per dose.

\section{Tissue barrier integrity assessment}

\section{Transepithelial electrical resistance (TEER) measurement}

Changes in barrier integrity of the EpiIntestinal ${ }^{\mathrm{TM}}$ tissues were assayed using Transepithelial electrical resistance (TEER) with an EVOM volt-ohmmeter equipped with an EndOhm electrode chamber (World Precision Instruments, Sarasota, FL), according to the manufacturer's published protocols. Raw resistance values $(\Omega)$ were converted to 
TEER readings $\left(\Omega \mathrm{cm}^{2}\right)$ by multiplying the raw measurements of each tissue by the surface area of the cell culture inserts $\left(0.6 \mathrm{~cm}^{2}\right)$.

\section{FITC-dextran tissue permeability assay}

Changes induced to the barrier function of the EpiIntestinal $^{\mathrm{TM}}$ tissues were monitored using fluorescein isothiocyanate (FITC)-dextran 20 kDa (FD20, Sigma Aldrich, St Louis, MO) tissue permeability assay. The tissue intactness was measured in EpiIntestinal ${ }^{\mathrm{TM}}$ tissues after adding $3 \mathrm{mg} /$ $\mathrm{ml}$ of FD20 to the apical culture media and incubating at $37^{\circ} \mathrm{C}$, for $2 \mathrm{~h}$ in $5 \% \mathrm{CO}_{2} / 95 \%$ air. The permeation of FD20 into the basolateral culture medium was determined with a microplate reader (SpectraMax M5, Molecular Devices, San José, CA) at 485/530 nm. FD20 permeation from the donor medium to the receiver medium was normalized to FD20 that permeated through blank inserts. Tissue barrier integrity was considered intact if FD20 permeability was less than $4 \%$.

\section{Histology and immunofluorescence}

3D EpiIntestinal ${ }^{\mathrm{TM}}$ tissues were immersed in $15 \%$ and $30 \%$ sucrose consecutively for $1 \mathrm{~h}$ at room temperature, and snapfrozen in Optimal Cutting Temperature freezing medium (Tissue-Tek ${ }^{\circledR}$, Torrance, CA). The samples were further processed into $25 \mu \mathrm{m}$-thick sections and incubated with primary antibodies against villin (sc-58897, Santa Cruz Biotechnology, Inc, Santa Cruz, CA), followed by appropriate Alexa Fluor 488- or 594-conjugated secondary antibodies (Molecular Probes; Thermo Fisher Scientific, Waltham, MA). Samples were counterstained with 4',6-diamidino2-phenylindole (DAPI, Sigma-Aldrich, St Louis, MO). To visualize F-actin filaments, samples were incubated with Alexa Fluor 488-labeled phalloidin (A12379; Life Technologies; Thermo Fisher Scientific, Waltham, MA) and counterstained with DAPI. Images were captured at room temperature using a fluorescence microscope (Zeiss AxioImager Z1; Carl Zeiss, Oberkochen, Germany), or confocal microscope (Olympus FV1000, Tokyo, Japan) with a Texas red, GFP, or DAPI filter. Image analysis was performed using Zeiss image analysis software, ZEN Pro Version 2.0 (Zeiss Microscopy, Jena, Germany).

\section{Tissue viability}

Viability was assessed in EpiIntestinal ${ }^{\mathrm{TM}}$ tissues using Alamar blue (resazurin sodium salt, R7017, Sigma Aldrich, St Louis, MO). The tissues were rinsed twice with HBSS with calcium and magnesium and transferred to a 24-well plate. Alamar blue at desired working concentration was added to apical compartment of the tissues and incubated in a $37^{\circ} \mathrm{C}, 5 \% \mathrm{CO}_{2} / 95 \%$ air, $98 \%$ humidity, incubator for $1.5 \mathrm{~h}$. The changes in fluorescence of the Alamar blue dye conversion was measured (excitation $560 \mathrm{~nm}$ and emission $590 \mathrm{~nm}$ ) in each sample well using a microplate reader (SpectraMax M5, Molecular Devices, San José, CA).

\section{SEM}

To visualize the columnar morphology of the intestinal 3D-RHE tissue, scanning electron microscopy was performed. Briefly, the tissue was fixed with a mixture of $4 \%$ paraformaldehyde (Sigma-Aldrich, St Louis, MO) and 2\% glutaraldehyde (Invitrogen; Thermo Fisher Scientific, Waltham, MA) solution overnight at room temperature (RT). Subsequently, the tissue was cut into equal pieces and postfixed/stained with $2 \%$ osmium tetraoxide (Sigma-Aldrich, St Louis, MO) for $1 \mathrm{~h}$. Excess stain was removed by washing with PBS. Tissue samples were then serially dehydrated with an ascending series of ethanol $(25 \%, 50 \%, 75 \%, 95 \%$, 100\%) 15 min each at RT. The dehydrated tissues were then immersed in hexamethyldisilazane (HMDS; Sigma Aldrich, St Louis, MO) for $10 \mathrm{~min}$, followed by air drying in a desiccator. The dried samples were then mounted on to a SEM sample stub, sputtered with gold and viewed in the SEM (Jeol JSM-6360LV, Tokyo, Japan).

\section{Statistical analysis}

All data are presented as means \pm standard error of mean. Two-tailed Student's $t$ test was used to determine the significance between two groups and data was deemed significant if $p<0.05$. All experiments were performed three times independently. Each experiment consisted of a single microtissue per dose unless otherwise indicated in figure legends.

\section{Results}

\section{Characterization of 3D reconstructed human small intestine model}

The EpiIntestinal ${ }^{\mathrm{TM}}$ microtissue is a 3D-RHE technology platform designed to provide a route-appropriate and species-specific system for laboratory-based applications including biochemical, pharmacological and toxicological analyses. To assess the feasibility of utilizing EpiIntestinal ${ }^{\mathrm{TM}}$ microtissues to evaluate responses to ingested particles, compounds and genotoxic reagents via an established MN assay protocol, we first examined the structure and architecture of the reconstructed tissue using scanning electron microscopy (SEM) (Fig. 1). We confirmed the tissue was stratified with apical-basal polarization, villi structures (Fig. 1a, left panel), brush-border morphology and microvilli 
Fig. 1 EpiIntestinal ${ }^{\mathrm{TM}}$ tissue recapitulates unique $3 \mathrm{D}$ tissue architecture and barrier function of normal human small intestines. a SEM was used to visualize villi (left panel) and microvilli (right panel) structures on EpiIntestinal ${ }^{\mathrm{TM}}$ tissue. Scale bar $=10 \mu \mathrm{m}$. b Immunofluorescence staining identifies villin (green) and DNA stain (blue) in the 3D EpiIntestinal reconstructed microtissue. Scale bar $=10 \mu \mathrm{m}$. c F-actin (green) and DAPI (blue) immunohistochemical staining of cryosections $(25 \mu \mathrm{m})$ of OCT embedded, EpiIntestinal $^{\mathrm{TM}}$ tissue. Scale bar $=20 \mu \mathrm{m}$. d Alamar blue viability assay of 3D tissue. e TEER measurement of tissue barrier integrity and f FITC-dextran assay of tissue permeability. The results from three independent experiments are shown. Each experiment consisted of a single microtissue per test condition. $* * * p<0.001$ a
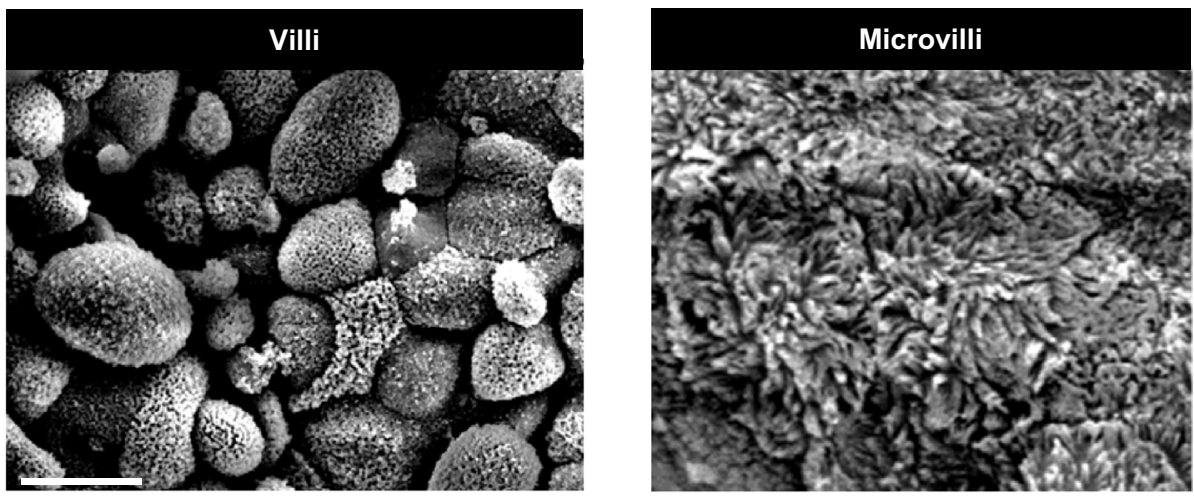

b

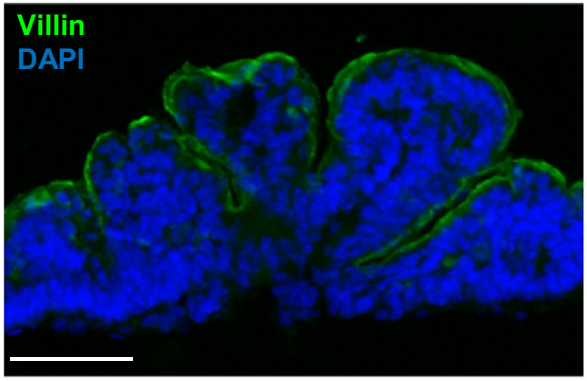

C F-actin

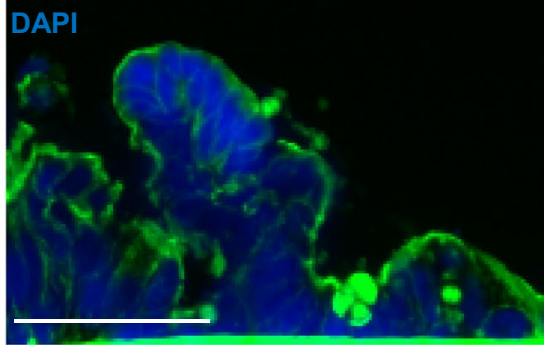

d

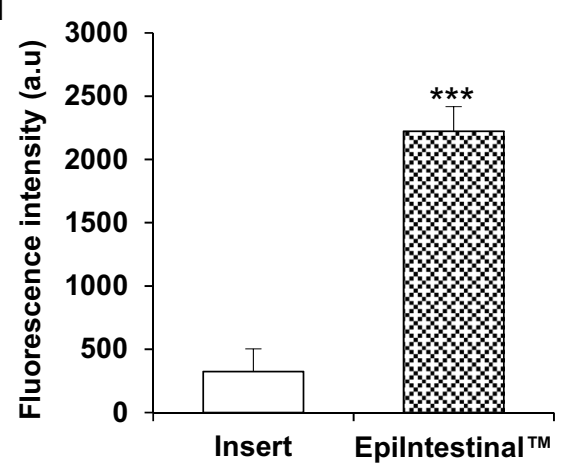

e

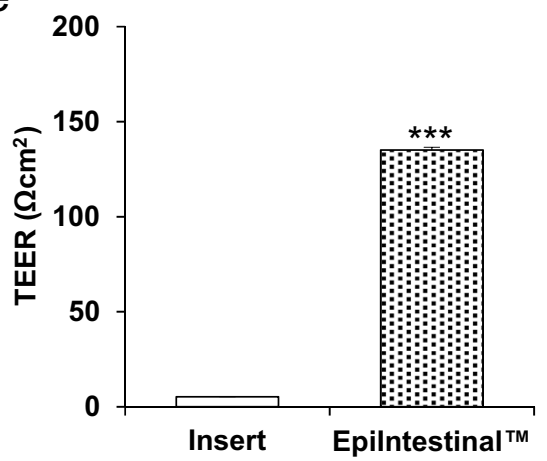

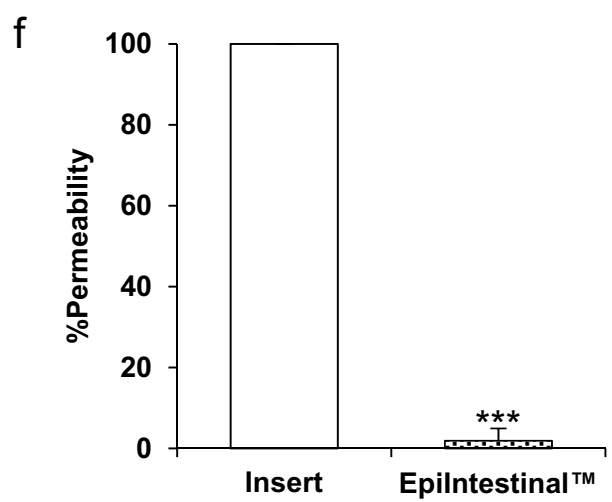

(Fig. 1a, right panel). Epifluorescence microscopy revealed in vivo-like tissue architecture with intestinal villi structures and columnar epithelium expressing villin (intestinal cell differentiation marker) (Fig. 1b). The presence of villi in the 3D-RHE microtissue construct provides substantially greater surface area to facilitate the uptake of test substances than is available in 2D cell culture models. Qualitative immunohistology analyses verify EpiIntestinal ${ }^{\mathrm{TM}}$ tissues exhibit apical-basal polarity with a highly developed, F-actin-rich, apical brush border of absorptive epithelial cells (Fig. 1c). 
The tissue constructs remain viable (Fig. 1d) and maintain barrier integrity yielding average measure of TransEpithelial Electrical Resistance (TEER) of $135 \pm 1.5 \Omega \mathrm{cm}^{2}$ (Fig. 1e), equivalent to in vivo physiological TEER measures of 50-100 $\Omega \mathrm{cm}^{2}$ (Amidon et al. 2000; Srinivasan et al. 2015; Takenaka et al. 2016). The TEER measured in EpiIntestinal $^{\mathrm{TM}}$ tissues is significantly lower than TEER reported for Caco-2 monolayer cells $\left(250-4000 \Omega \mathrm{cm}^{2}\right.$ ) (Amidon et al. 2000). We also conducted fluorescein isothiocyanate (FITC)-dextran permeability assays, a complementary measure of barrier integrity, yielding average permeability $2.25 \% \pm 0.8$ (Fig. 1f).

\section{Development of MN cytome assay protocol in 3D reconstructed Epilntestinal ${ }^{\mathrm{Tm}}$ tissue}

OECD guidelines for the testing of chemicals and substances which are potentially genotoxic and carcinogenic, that induce genetic damage, recommend the micronucleus assay protocol (OECD 2016b). There are several versions of the test (OECD 487) designed to detect micronuclei originating from acentric chromosome fragments (i.e. lacking a centromere) in the cytoplasm of interphase cells, or whole chromosomes that are unable to migrate to the poles during the anaphase stage of cell division. The guideline allows protocols to be conducted either in the presence, or in the absence of cytokinesis blockage, depending on the intention of the treatment, types of tissue/cell models, genotoxic mechanisms, as well as whether the cell population analysed has undergone sufficient division. The in vitro cytokinesis block micronucleus (CBMN) assay is the version most commonly used (Llewellyn et al. 2020; Fenech et al. 1991; Fenech 2007). In the CBMN assay, affected cells (after cell division) are recognized by their binucleated (BN) phenotype after cell division is blocked with Cyt-B, a highly specific disruptor of microfilament assembly required for the completion of cell division (Fenech 2000; Fenech and Morley 1985a, 1985b, 1986; Carter 1967). To determine sensitivity of proliferating cells in EpiIntestinal ${ }^{\mathrm{TM}}$ microtissues to Cyt-B, we treated the 3D tissues apically and basolaterally for 10 days with $6 \mu \mathrm{g} / \mathrm{ml}$ of Cyt-B. Approximately eight percent (8.1\%) of cells isolated from EpiIntestinal ${ }^{\mathrm{TM}}$ microtissues exposed to Cyt-B contained BN, the majority $(91.9 \%)$ were phenotypically normal: i.e. mononuclear (Fig. 2a, b). Notably, the $\mathrm{BN}$ population is an underestimation of cell proliferation in the 3D tissue due to rapid intestinal cell turnover and shedding via the apical (luminal) surface. To provide a more comprehensive analysis of genotoxicity, mitotic dysfunction and cell death, we developed and optimised a MN cytome protocol in which the $\mathrm{MN}$ frequency in the mononucleated cell populations (without Cyt-B), reflects 3D EpiIntestinal ${ }^{\mathrm{TM}}$ responses to long-term treatment regimen (Fig. 2c).
In contrast to commonly used in vitro models such as TK6, or human lymphocytes, in vitro proliferation of 3D EpiIntestinal ${ }^{\mathrm{TM}}$ is not dissimilar to intestinal epithelia in vivo (Altay et al. 2019). To allow longer exposure period, our protocol uses a repetitive, 10-day test article exposure, every $48 \mathrm{~h}$ from day $0-6$. To control dehydration and media exhaustion subsequent to sustained metabolic activity, we increased treatment frequency to 24-hourly from day 6 to day 9; tissues were harvested at day 10 . Prolonging tissue exposure to test articles provides sufficient time for cells in EpiIntestinal $^{\mathrm{TM}}$ tissue to traverse more than one cell cycle. Test articles were added to the apical side of the Transwell ${ }^{\mathrm{TM}}$ to recapitulate native interactions with test compounds and materials as they occur in vivo. Distinct cell phenotypes and nuclear anomalies are evident in the 3D EpiIntestinal ${ }^{\mathrm{TM}} \mathrm{MN}$ cytome assay (Fig. 2d). These were identified using detailed criteria as described by Bolognesi, et al. (Bolognesi et al. 2013) and included micronuclei and nuclear buds, mononucleated (basal and differentiated) cells, binucleated cells, condensed chromatin, karyorrhectic, pyknotic and karyolytic cells. Our scoring protocol was adopted and modified from the approach developed by Thomas et al. (Thomas et al. 2009). One thousand total cells were scored per microtissue. The results were recorded from three independent experiments. Each experiment consisted of a single microtissue per dose.

Scorable MN are formed during anaphase of mitosis. It is necessary to demonstrate that cells scored in the assay have completed mitosis and undergone division during, or following, exposure to the test articles, to minimise false negative responses. The completion of mitosis is determined through assessment of EpiIntestinal ${ }^{\mathrm{TM}}$ tissue proliferation. We cultured the EpiIntestinal ${ }^{\mathrm{TM}}$ tissue over 11 days' after receipt and monitored tissue growth. The EpiIntestinal ${ }^{\mathrm{TM}}$ cell number was observed to increase by $30 \%$ (population doubling, PD: 0.3) after 7 days and by $80 \%$ (PD: 0.8) after 11 days' cultivation (Fig. 3a). In contrast, TK6 cell populations were observed to increase $400 \%$ (PD: 4) after 2 days, and $600 \%$ (PD: 6) after 3 days (Fig. 3b). It is important to note that these quantitative measures of $3 \mathrm{D}$ EpiIntestinal ${ }^{\mathrm{TM}}$ tissue proliferation do not account for cell shedding from the apical (luminal) intestinal epithelial surface, a manifestation of intestinal homeostasis.

\section{Evaluation of background micronuclei frequency in 3D Epilntestinal ${ }^{\mathrm{TM}}$ tissue}

A key determinant of MN assay sensitivity is the basal, or endogenous prevalence of $\mathrm{MN}$ in a cell culture, or a tissue model/construct. Under normal circumstances the formation of $\mathrm{MN}$ is a rare event, tissue homeostasis and genome stability is rigorously maintained by redundant DNA repair machinery and active cell cycle checkpoints; DNA damage 
Fig. 2 Development of MN cytome assay in EpiIntestinal $^{\mathrm{TM}}$ tissue. a Prevalence of binucleated $(\mathrm{BN})$ and mononucleated (Mono) cells dissociated from EpiIntestinal ${ }^{\mathrm{TM}}$ tissue following 10 days' cytochalasin B exposure. One thousand total cells per microtissue were scored to determine the percentage of mononucleated and binucleated cells. b Microscopic images of $\mathrm{BN}$ and Mono cells dyed with acridine orange. Scale bar $=10 \mu \mathrm{m}$. $\mathbf{c}$ Treatment regimen of 3D EpiIntestinal ${ }^{\mathrm{TM}}$ tissue over 10 days. $\mathbf{d}$ Various cell types and nuclear anomalies identified and evaluated in MN cytome assay. The Mitomycin $\mathrm{C}(2 \mu \mathrm{g} / \mathrm{ml})$ treated EpiIntestinal $^{\mathrm{TM}}$ tissue were dissociated, fixed and differentially stained with acridine orange (see "Materials and methods"). Scale bar $=10 \mu \mathrm{m}$. The results from three independent experiments are shown. Each experiment consisted of a single microtissue per test condition. $* * * p<0.001$ a

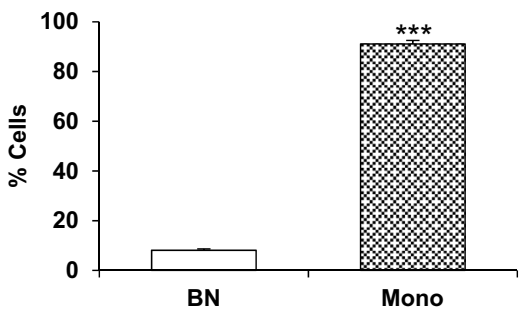

C

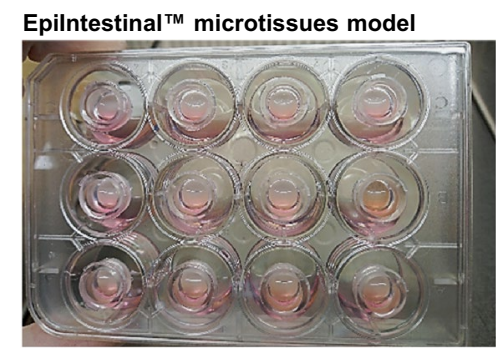

b

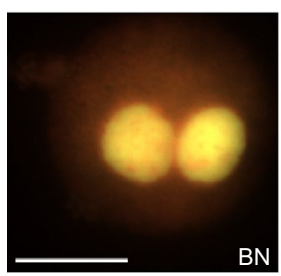

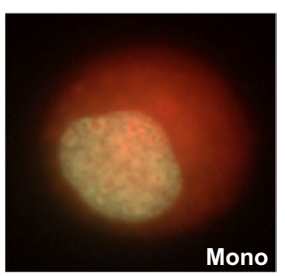

Day -1

Epilntestinal ${ }^{\mathrm{TM}}$ microtissues revived with prewarmed culture medium overnight

Day 0 to 6

Microtissues rinsed with $1 \times$ HBSS, dosed apically every $48 \mathrm{~h}$ with test articles (day $0,2 \& 4$ ) and returned to incubator.

Day 6 to 9

Microtissues rinsed with $1 \times$ HBSS (day 6 \& 8 only), dosed apically every $24 \mathrm{~h}$ with test articles and returned to incubator.

Day 10

Microtissues harvested for micronuclei analysis

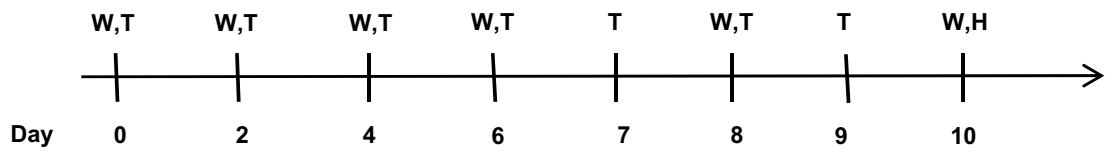

${ }^{*} \mathrm{~W}=$ wash, $\mathrm{T}=$ treat, $\mathrm{H}=$ harvest

d

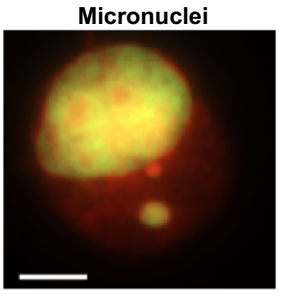

Nuclear bud

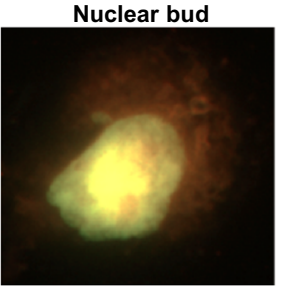

Karyolysis

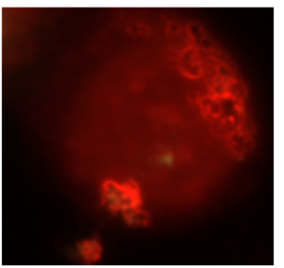

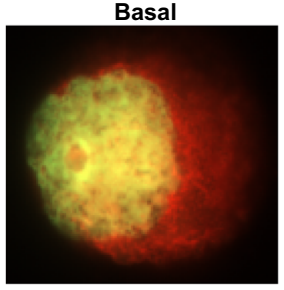

Condensed chromatin

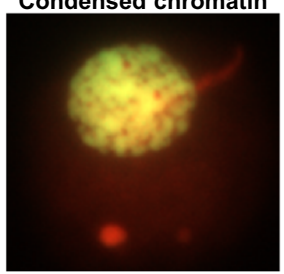

Differentiated

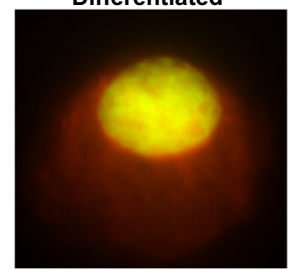

Karyorrhexis

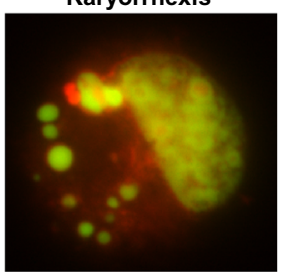

Binucleated

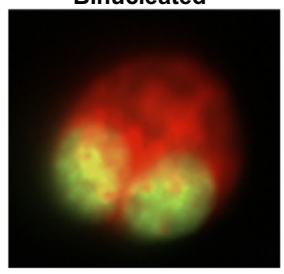

Pyknosis

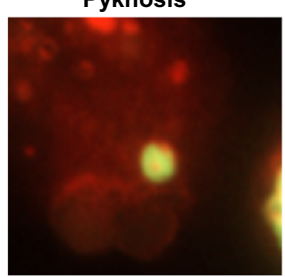

is promptly repaired to ensure the quality and integrity of the genome (Jayakumar and Kasturi 2020; Luzhna et al. 2013). As an epithelial in vitro model system EpiIntestinal ${ }^{\mathrm{TM}}$ tissue maintains a relatively high rate of cellular proliferation, baso-apical migration, apoptosis and cell shedding, in common with native human small intestine (Bullen et al. 2006). Shed cells are not removed from the system, as they would be in native tissue by peristalsis. Thus fragments from shed cells, including DNA particles, microvesicles and apoptosomes, are sources of contamination that may 


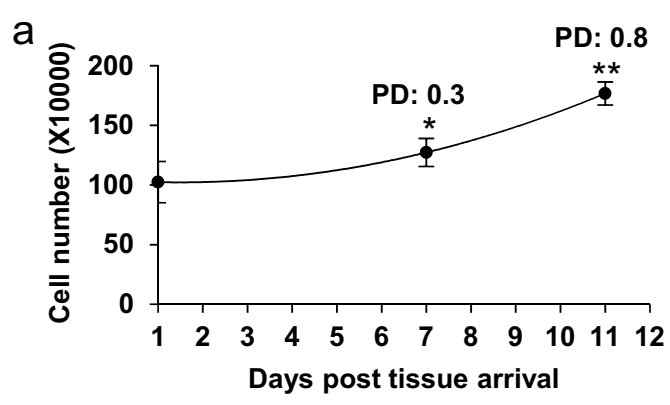

Fig. 3 Assessment of cell proliferation in EpiIntestinal ${ }^{\mathrm{TM}}$ tissue. a Cell proliferation of EpiIntestinal ${ }^{\mathrm{TM}}$ tissue harvested at day 1, 7 and 11 post tissue arrival. $\mathrm{PD}=$ population doubling. $\mathbf{b}$ TK6 cell prolifera- b

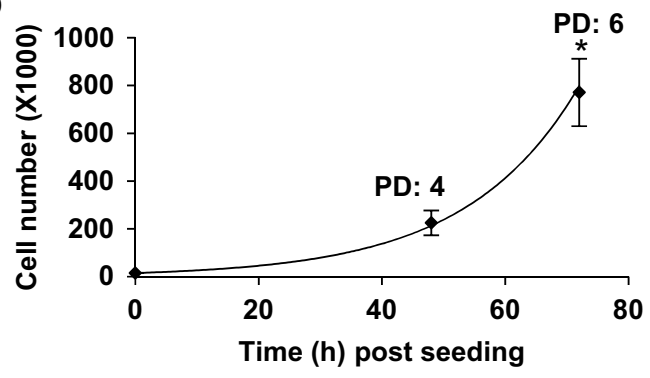

tion at $48 \mathrm{~h}$ and $72 \mathrm{~h}$ post cell seeding. The results from three independent experiments are shown. Each experiment consisted of a single microtissue per test condition. $* p<0.05$ and $* * p<0.01$ a
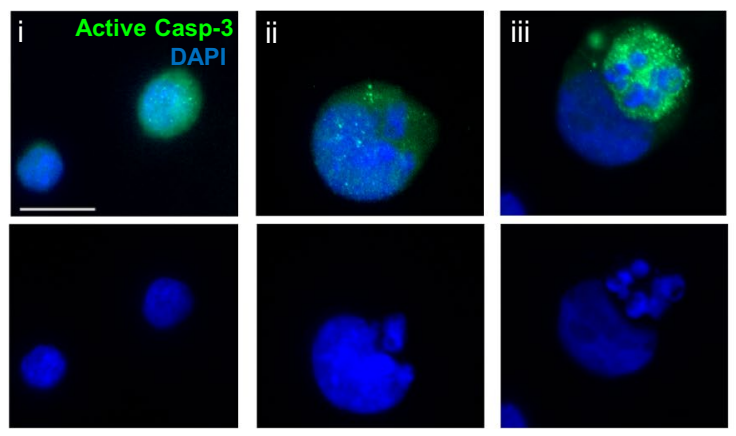

b

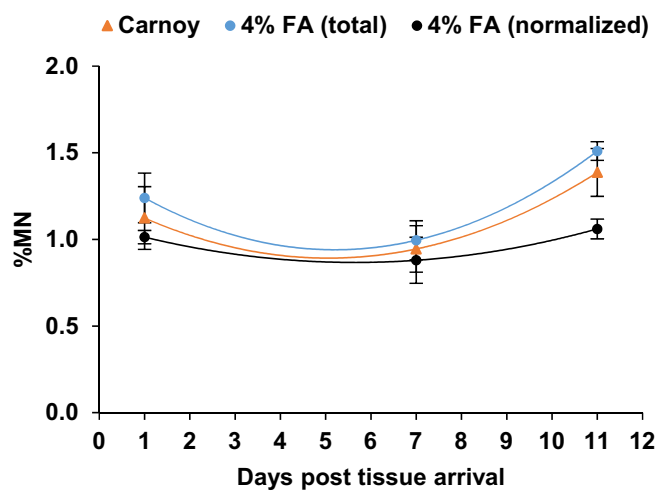

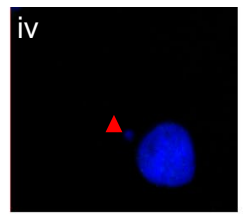
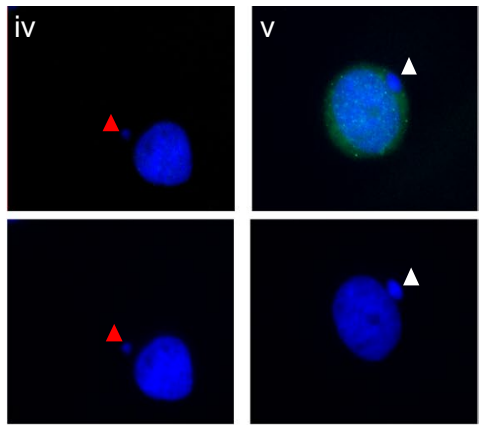

Fig. 4 Prevalence of background micronuclei (MN) in EpiIntestinal $^{\mathrm{TM}}$ tissue. a Immunofluorescence staining of active caspase-3 (green) and DAPI (blue) in 0.1\% DMSO (solvent) treated EpiIntestinal $^{\mathrm{TM}}$ tissue, differentiate early apoptotic cells (i-iii) and genuine MN (red arrow, iv) from DNA fragment(s) stemming from early apoptotic cells (white arrow, v). Scale bar $=10 \mu \mathrm{m}$. b Prevalence of basal MN in EpiIntestinal ${ }^{\mathrm{TM}}$ tissue on day 1,7 and 11. Dissociated single cells were fixed in Carnoy's fixative and $4 \%$ formaldehyde (FA). 4\% FA (total) represents total basal $\mathrm{MN}$ scored from the fixed cells, while $4 \%$ FA (normalized) represents the population of $\mathrm{MN}$ after exclusion of DNA fragment(s) stemming from early apoptotic cells in the same samples. One thousand total cells were scored per microtissue. The results from three independent experiments are shown. Each experiment consisted of a single microtissue per test condition be mistaken for $\mathrm{MN}$, and inflate measures of background MN (Lukamowicz et al. 2011). To address this potential confounder, we optimized the exposure of EpiIntestinal ${ }^{\mathrm{TM}}$ tissue to test articles, washing EpiIntestinal ${ }^{\mathrm{TM}}$ tissue constructs with HBSS every 2 days to minimise basal MN and microvesicle contamination (Fig. 2c). We assayed for active caspase-3, to detect pre-apoptotic cells (Belloc et al. 2000; Zhang et al. 2013); the expression of active caspase-3 was detected prior to the onset of apoptosis-induced DNA fragmentation (Fig. 4a(i)) and the formation of MN. Expression intensified with increasing severity of DNA fragmentation in apoptotic cells (Fig. 4a(ii)-4a(iii)). Thus, detecting active 
caspase-3 is able to resolve "DNA fragment(s)" stemming from apoptotic cells (Fig. 4a(v)) from authentic MN from unrepaired DNA damages (Fig. 4a(vi)), and eliminate false positives from $\mathrm{MN}$ assay measures. We determined the background prevalence of $\mathrm{MN}$ in EpiIntestinal ${ }^{\mathrm{TM}}$ tissue after 1 day and 6 days' exposure to 0.1\% DMSO, finding the prevalence of $\mathrm{MN}$ was $\sim 1.1 \%$. The background prevalence of $\mathrm{MN}$ increased to $1.5 \%$ in tissues harvested at day 11 , however, this was not significantly different to tissues exposed for shorter periods (Fig. 4b). Interestingly, when we excluded DNA fragment(s) stemming from apoptotic cells from the total MN count, normalized day $11 \mathrm{MN}$ counts yielded $1.0 \%$, equivalent to the basal level of $\mathrm{MN}$ observed at day 1 and 6 (Fig. 4b). We are confident our result is sufficiently accurate for data normalization using DMSO-treated tissues when determining the prevalence of $\mathrm{MN}$ in samples exposed to test articles using the optimized MN cytome assay protocol.

\section{Genetic toxicity assessment of 3D Epilntestinal ${ }^{\mathrm{Tm}}$ tissues exposed to reference genotoxin}

To demonstrate the validity of the optimized MN cytome assay protocol to detect clastogenic and aneugenic compounds, and the effectiveness of the metabolic activation system, we exposed 3D EpiIntestinal ${ }^{\mathrm{TM}}$ tissues to reference genotoxins: clastogen (mitomycin c); clastogen requiring metabolic activation (benzo(a)pyrene); and aneugen (vinblastine sulphate). The responses of 3D EpiIntestinal ${ }^{\mathrm{TM}}$ tissue samples to the reference genotoxins is presented in Fig. 5. Significant decreases in cell population were observed in the 3D tissues exposed to doses $\geq 0.2 \mu \mathrm{g} / \mathrm{ml}$ mitomycin C, $500 \mathrm{ng} / \mathrm{ml}$ vinblastine sulphate and $\geq 6.25 \mu \mathrm{g} / \mathrm{ml}$ (benzo(a) pyrene). Significant dose-dependent induction of MN was also evident in 3D EpiIntestinal ${ }^{\mathrm{TM}}$ tissues exposed to any dose of these reference chemicals, compared to 3D EpiIntestinal $^{\mathrm{TM}}$ tissues exposed to DMSO control samples. We assayed for active caspases-3 as a measure of basal MN, and to exclude DNA fragment(s) stemming from apoptotic cells from our MN analysis. We noted that consistency was high between measures of $\mathrm{MN}$ whether tissue samples were fixed in Carnoy's fixative or 4\% formaldehyde. In this study, EpiIntestinal $^{\mathrm{TM}}$ tissues were dissociated and scored for nuclear anomalies (nuclear buds, binucleated, condensed chromatin, karyorrhectic, pyknotic and karyolytic cells), and for micronuclei in mononucleated cells (Table 1). We observed a dose-dependent increase in karyorrhectic cells in every tissue sample exposed to the genotoxins. Notably, the frequency of pyknotic and karyolytic cells was also increased in tissue samples exposed to vinblastine sulphate. a

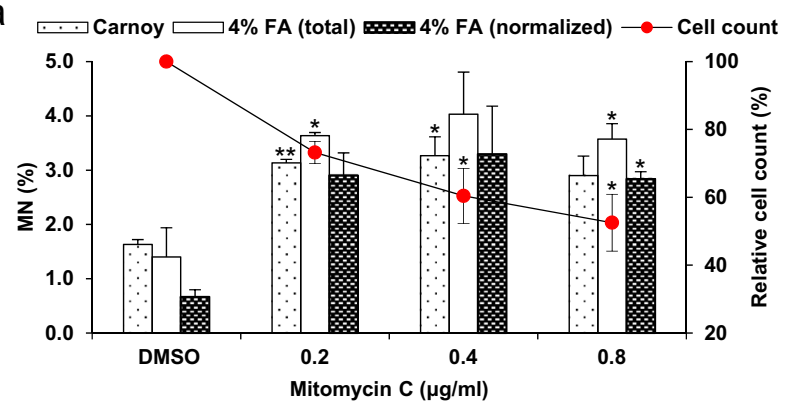

b

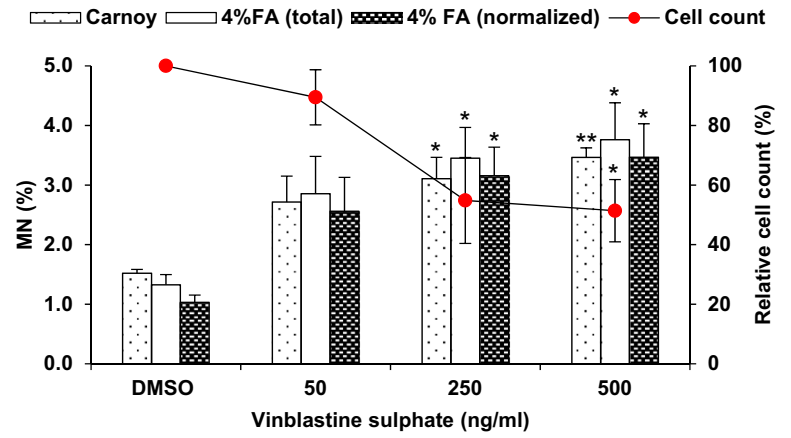

C

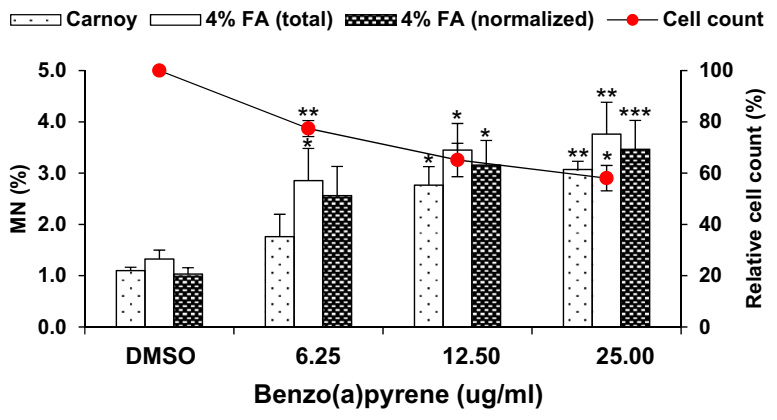

Fig. 5 Genotoxicity assessment of reference chemicals exposed-3D EpiIntestinal $^{\mathrm{TM}}$ tissue. Tissues were exposed to test articles: a mitomycin $\mathbf{C}, \mathbf{b}$ vinblastine sulphate, and $\mathbf{c}$ benzo(a)pyrene; for 10 days via apical treatment. Genotoxicity was assessed until cell viability was decreased by approximately $50 \%$. Tissues were dissociated to single cells, fixed in Carnoy's fixative and $4 \%$ formaldehyde (FA) and scored according to the criteria described in "Materials and methods". 4\% FA (total) represents total MN scored from the fixed cells, while 4\% FA (normalized) represents the population of $\mathrm{MN}$ after exclusion of DNA fragment(s) stemming from early apoptotic cells from the MN scoring. One thousand total cells were scored per microtissue to determine the frequency of $\mathrm{MN}$ induction. The results from three independent experiments are shown. Each experiment consisted of a single microtissue per test dose. ${ }^{*} p<0.05$, $* * p<0.01$ and $* * * p<0.001$

\section{RICyt assay differentiates genotoxins from non-genotoxin}

To further demonstrate the accuracy of RICyt assay in hazard identification, we exposed 3D EpiIntestinal ${ }^{\mathrm{TM}}$ tissues with mitomycin $\mathrm{C}$, a known genotoxin, and phenformin $\mathrm{HCl}$, 
Table 1 Cell phenotype and nuclear anomalies in 3D EpiIntestinal ${ }^{\mathrm{TM}}$ tissue

\begin{tabular}{|c|c|c|c|c|c|c|c|c|}
\hline MMC $(\mu \mathrm{g} / \mathrm{ml})$ & MN & Buds & Mono & $\mathrm{BN}$ & CC & $\mathrm{KR}$ & PY & $\mathrm{KL}$ \\
\hline DMSO & $1.63 \pm 0.09$ & $1.10 \pm 0.51$ & $89.43 \pm 1.40$ & $1.47 \pm 0.23$ & $0.23 \pm 0.15$ & $5.17 \pm 0.75$ & $0.40 \pm 0.00$ & $0.57 \pm 0.17$ \\
\hline 0.2 & $3.13 \pm 0.07^{* *}$ & $0.50 \pm 0.10$ & $87.53 \pm 0.94$ & $1.57 \pm 0.19$ & $0.37 \pm 0.09$ & $6.23 \pm 0.61$ & $0.17 \pm 0.09$ & $0.50 \pm 0.10$ \\
\hline 0.4 & $3.27 \pm 0.35^{*}$ & $0.60 \pm 0.21$ & $86.67 \pm 0.70$ & $1.60 \pm 0.26$ & $0.07 \pm 0.07$ & $7.43 \pm 0.73^{\star *}$ & $0.33 \pm 0.15$ & $0.33 \pm 0.03$ \\
\hline 0.8 & $2.90 \pm 0.36$ & $0.67 \pm 0.15$ & $88.23 \pm 1.13$ & $1.23 \pm 0.03$ & $0.13 \pm 0.07$ & $6.33 \pm 0.83$ & $0.37 \pm 0.18$ & $0.17 \pm 0.09$ \\
\hline VB (ng/ml) & $\mathrm{MN}$ & Buds & Mono & $\mathrm{BN}$ & $\mathrm{CC}$ & $\mathrm{KR}$ & PY & $\mathrm{KL}$ \\
\hline DMSO & $1.52 \pm 0.07$ & $0.78 \pm 0.23$ & $91.01 \pm 1.48$ & $0.57 \pm 0.09$ & $0.03 \pm 0.03$ & $4.42 \pm 1.24$ & $0.70 \pm 0.20$ & $0.98 \pm 0.42$ \\
\hline 50 & $2.71 \pm 0.44$ & $0.63 \pm 0.29$ & $89.09 \pm 1.25$ & $0.77 \pm 0.12$ & $0.07 \pm 0.03$ & $4.90 \pm 0.63$ & $0.6 \pm 0.12$ & $1.23 \pm 0.74$ \\
\hline 250 & $3.11 \pm 0.36^{*}$ & $0.53 \pm 0.28$ & $87.14 \pm 2.07$ & $0.86 \pm 0.38$ & $0.15 \pm 0.13$ & $4.75 \pm 1.30$ & $1.66 \pm 0.49$ & $1.82 \pm 1.01$ \\
\hline 500 & $3.46 \pm 0.16^{\star \star}$ & $0.50 \pm 0.16$ & $84.89 \pm 3.06$ & $0.94 \pm 0.49$ & $0.17 \pm 0.02^{* *}$ & $6.48 \pm 2.52$ & $1.77 \pm 0.77$ & $1.79 \pm 1.05$ \\
\hline $\mathrm{BaP}(\mathrm{ug} / \mathrm{ml})$ & $\mathrm{MN}$ & Buds & Mono & BN & $\mathrm{CC}$ & $\mathrm{KR}$ & PY & $\mathrm{KL}$ \\
\hline DMSO & $1.10 \pm 0.12$ & $0.47 \pm 0.09$ & $92.37 \pm 0.74$ & $1.23 \pm 0.09$ & $0.17 \pm 0.12$ & $3.77 \pm 0.49$ & $0.33 \pm 0.03$ & $0.57 \pm 0.15$ \\
\hline 6.25 & $1.76 \pm 0.29$ & $0.43 \pm 0.22$ & $89.96 \pm 0.56$ & $1.30 \pm 0.12$ & $0.13 \pm 0.03$ & $5.59 \pm 0.41^{*}$ & $0.23 \pm 0.03$ & $0.60 \pm 0.25$ \\
\hline 12.50 & $2.77 \pm 0.18^{*}$ & $0.90 \pm 0.15^{*}$ & $85.87 \pm 1.30$ & $1.80 \pm 0.38$ & $0.37 \pm 0.22$ & $7.27 \pm 1.07$ & $0.40 \pm 0.21$ & $0.63 \pm 0.23$ \\
\hline 25.00 & $3.07 \pm 0.19^{* *}$ & $0.43 \pm 0.08$ & $88.11 \pm 1.01$ & $0.99 \pm 0.29$ & $0.20 \pm 0.10$ & $6.24 \pm 0.06^{*}$ & $0.56 \pm 0.33$ & $0.40 \pm 0.20$ \\
\hline
\end{tabular}

MN, micronuclei; Buds, nuclear buds, Mono, mononucleated cells (basal and differentiated); BN, binucleated cells;

$\mathrm{CC}$, condensed chromatin; KR, karyorrhexis; PY, pyknosis; KL, karyolysis

MMC, mitomycin C; VB, vinblastine sulphate; BaP, benzo(a)pyrene

Reference genotoxins were applied to the apical surface of 3D EpiIntestinal ${ }^{\mathrm{TM}}$ tissues for 10 days, as described in "Materials and methods". Tissues were dissociated into single cell suspensions and fixed in Carnoy's fixative. One thousand total cells were scored per microtissue to determine the frequency of MN and cytome induction. The results from three independent experiments are shown. Each experiment consisted of a single microtissue per test dose. Data are reported as percentage (mean $\pm \mathrm{SE}$ )

$M N$ micronuclei, Buds nuclear buds, Mono mononucleated cells (basal and differentiated), $B N$ binucleated cells, $C C$ condensed chromatin, $K R$ karyorrhexis, $P Y$ pyknosis, $K L$ karyolysis, $M M C$ mitomycin C, $V B$ vinblastine sulphate, $B a P$ benzo(a)pyrene

$* p<0.05$ and $* * p<0.01$

a known non-genotoxin, using the regimen reported earlier (Fig. 2c). After 10 days' exposure to mitomycin C, the prevalence of $\mathrm{MN}$ was found to increase by $3 \%$, accompanied by a corresponding decline of $60 \%$ in the viable cell population (Fig. 6). In contrast, no genotoxicity was detected in tissues exposed to phenformin $\mathrm{HCl}$. The prevalence of $\mathrm{MN}$ in phenformin $\mathrm{HCl}$ treated-tissue constructs was $\sim 1 \%$, indistinguishable from the DMSO control (1.5\%). Although nongenotoxic, cells in 3D tissues exposed to phenformin $\mathrm{HCl}$ did exhibit dose-dependent cytotoxicity. Tissues exposed to $62.5,125$ and $250 \mu \mathrm{g} / \mathrm{ml}$, exhibited $40 \%, 45 \%$ and $60 \%$ loss of viable cell populations, respectively (Fig. 6a). These data are comparable with observations acquired from a parallel study conducted using the 2D cell culture TK6 cell line. After 24 h-exposure to mitomycin C, the prevalence of $\mathrm{MN}$ in TK6 cells was assayed to be $3.4 \%$, with a corresponding population decline of $55 \%$ (Fig. 6b). We did not detect any evidence of genotoxicity in TK6 cultures treated with phenformin $\mathrm{HCl}$, and the prevalence of $\mathrm{MN}(\sim 0.6 \%)$ were determined to be comparable across all concentrations tested, similar to cultures exposed to the DMSO control $(0.7 \%)$. The cytotoxic profile was similar to 3D EpiIntestinal ${ }^{\mathrm{TM}}$, with $35 \%, 40 \%, 50 \%$ and $60 \%$ cytotoxicity in samples across the dose range tested. These results indicate that responses assayed in the 3D EpiIntestinal ${ }^{\mathrm{TM}}$ microtissue constructs are comparable with conventional 2D cell culture assays and that the RICyt assay is able to discriminate genotoxic reagents from non-genotoxic reagents.

\section{Discussion}

The aim of this study was to evaluate whether the 3D EpiIntestinal ${ }^{\mathrm{TM}}$ platform of reconstructed microtissues is suitable for assessing the genotoxicity of ingested materials encountered by the human gut. We hypothesised that the human 3D EpiIntestinal ${ }^{\mathrm{TM}}$ tissue model is a suitable technology platform amenable to be adapted for evaluating the toxicity of ingested materials. To address this, we have developed a MN cytome assay protocol (RICyt assay). We report the findings of our evaluation, demonstrating that the 3D EpiIntestinal ${ }^{\mathrm{TM}}$ platform is capable of supporting hazard identification of orally ingested material. We show that $3 \mathrm{D}$ EpiIntestinal ${ }^{\mathrm{TM}}$ in vitro tissue is a micro-mimic of human small intestine: the live tissue model includes multiple cell types (enterocytes, paneth cells, M cells, tuft cells and intestinal stem cells), lamina propria, polarised phenotype, barrier functions and biochemical signature of native human intestinal tissue. The 3D EpiIntestinal ${ }^{\mathrm{TM}}$ model offers several advantages over current 2D monoculture protocols. It includes defined cell populations with polarised organisation characteristic of native intestine; the $3 \mathrm{D}$ EpiIntestinal $^{\mathrm{TM}}$ 
Fig. 6 RICyt assay distinguishes genotoxins from non-genotoxin. a The genotoxin, mitomycin $\mathrm{C}$, and nongenotoxic agent, phenformin $\mathrm{HCl}$, were applied to the apical surfaces of 3D EpiIntestinal ${ }^{\mathrm{TM}}$ in vitro model tissues at various doses for 10 days. Tissues were dissociated into single cell suspensions, fixed in Carnoy's fixative. One thousand total cells were scored per microtissue to determine the frequency of $\mathrm{MN}$ induction. Cell viability of treated 3D EpiIntestinal ${ }^{\mathrm{TM}}$ tissues are presented. The results from three independent experiments are shown. Each experiment consisted of a single microtissue per test dose. b A parallel study was conducted in which TK6 lymphocytic cells were exposed to mitomycin $\mathrm{C}$ and phenformin $\mathrm{HCl}$ at various doses for $24 \mathrm{~h}$. Single cell suspensions were then fixed and scored. One thousand cells had been scored per treated sample for $\mathrm{MN}$ induction. Cell viability profile of treated TK6 cells are presented. The TK6 MN data were generated from independent duplicates. ${ }^{*} p<0.05$, $* * p<0.01$ and $* * * p<0.001$

\section{a} $\mathrm{MN}(\%)$ Relative cell count (\%)
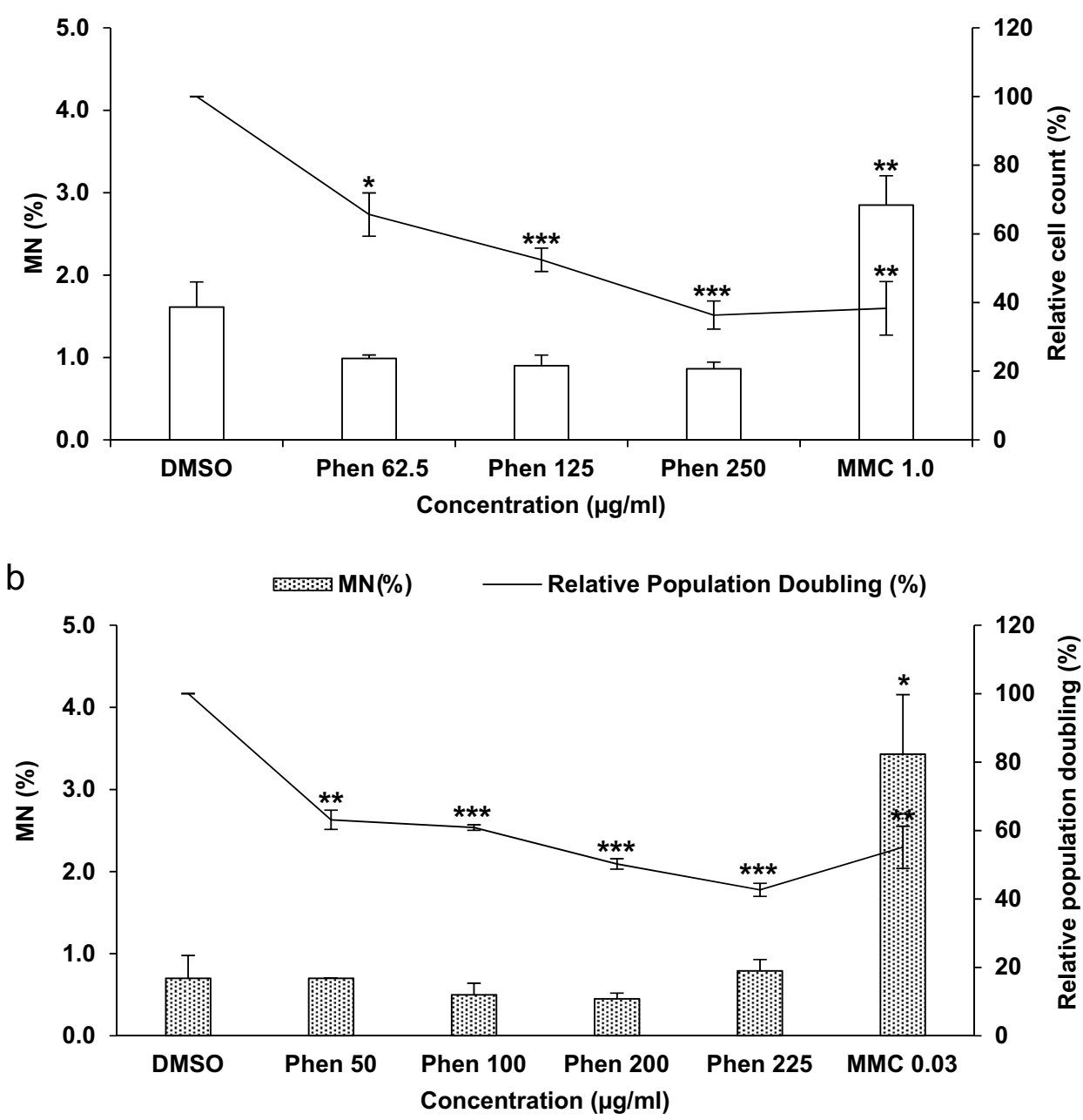

model can be maintained in vitro for a reasonable period of time ( $>10$ days), remaining proliferative, differentiating and shedding from the apical surface for the duration of the assay. Constitutive intestinal cell shedding, a feature of the 3D EpiIntestinal ${ }^{\mathrm{TM}}$ model, makes the classical CBMN assay protocol unsuitable for this platform. Consequently, we developed and optimized the RICyt assay protocol as a comprehensive multiple endpoint-approach to measure DNA damage and cell death in 3D in vitro tissues. Having a low and reproducible baseline MN frequency, the 3D EpiIntestinal $^{\mathrm{TM}}$ in vitro tissue model assures the RICyt assay is valid and accurate in detection of genotoxins and non-genotoxins, and producing more realistic and relevant responses to toxic agents than is available from protocols that utilise 2D monolayer cultures.

In vitro cells cultivated in $2 \mathrm{D}$ plastic vessels are neither physiological, nor systemic, and consequently fail to replicate the complexity inherent in intact tissues in vivo (Pridgeon et al. 2018). The evolution of in vitro 3D cell culture techniques and organotypic models is a promising approach to bridge the gap between $2 \mathrm{D}$ cell culture and in vivo organisms (OECD 2019, 2019). Recognising this, the OECD has published guidelines approving the use of reconstructed in vitro 3D tissue equivalents, including reconstructed human epidermis in vitro skin irritation test (OECD 439) (OECD 2019) and skin corrosion test (OECD 431) (OECD 2019). The 3D EpiIntestinal ${ }^{\mathrm{TM}}$ in vitro tissue used in this study offers relevant site of contact risk (apical surfaces of luminal villus), and accessibility to a comprehensive inventory of intestine-specific toxicity assays. Our data demonstrate that 3D EpiIntestinal ${ }^{\mathrm{TM}}$ maintains the complexity of native human intestinal epithelial architecture, its biochemistry, its physiology and its functionality, for up to 10 days in vitro. In addition, the $3 \mathrm{D}$ EpiIntestinal ${ }^{\mathrm{TM}}$ in vitro model has shown it is suitable for longer-term studies.

The MN assay was originally designed as a simple morphological assay to identify cells with post-mitotic chromosome breakage and/or whole chromosome loss, or dysfunctional chromosome segregation; events that requires mitosis, or meiotic division (Fenech 2007). Cyt-B is commonly used 
to block cytokinesis, leading to formation of BN cells, a convenient way to identify once-divided cells. However, we encountered a non-uniform block of cytokinesis because the 3D EpiIntestinal ${ }^{\mathrm{TM}}$ microtissues comprise unsynchronized cells in various stages of the cell cycle. While we could verify the $3 \mathrm{D}$ EpiIntestinal ${ }^{\mathrm{TM}}$ tissues maintained rapid cellular turnover of between 3 to 5 days (Umar 2010; Park et al. 2016; Creamer et al. 1961), extending treatment with Cyt-B up to 10 days did not improve the detection of post-mitotic cells. It is worth noting that intestinal epithelial homeostasis is maintained by a strict equilibrium between cell proliferation in the crypt, and cell shedding from the villus tip (Gregorieff et al. 2005; Byun et al. 2005). We interpret that the high cell proliferation evident in the 3D EpiIntestinal ${ }^{\mathrm{TM}}$ tissues coexists with a high rate of apical-luminal shedding, replicating the in vivo intrinsic mechanism maintaining intestinal barrier integrity and functionality (Günther et al. 2013; Doering et al. 2004; Gao and Wang 2009; Watson 2004). We suggest that active cell shedding likely resulted in the under-detection of post-mitotic cells; that the lower than expected prevalence of $\mathrm{BN}$ cells $(\sim 8.1 \%)$ we recorded in this study is not a true measure of endogenous cell proliferation in the 3D EpiIntestinal ${ }^{\mathrm{TM}}$ in vitro model.

In the adult gut, epithelial stem cells resident in the intestinal crypt, migrate upward, ascending adjacent villus as an epithelial 'conveyor belt'. Proliferation occurring in the crypt is balanced by intimate interactions with the underlying matrix that orchestrates proliferation, migration, differentiation, and, ultimately, cell death (detachmentdependent apoptosis) when intestinal epithelial (i.e. EpiIntestinal ${ }^{\mathrm{TM}}$ ) cells are shed from intestinal villus into the lumen (Bullen et al. 2006; Williams et al. 2015). Unlike the GI tract, the 3D EpiIntestinal ${ }^{\mathrm{TM}}$ in vitro model lacks in vivo processes (peristalsis, fluid shear) that expel shed cells from the villus surface. This is a potential confounder of the model, as DNA fragments in apoptotic cells may be difficult to distinguish from MN (Baldassarre et al. 2000). Therefore, apoptosis is significant event with potential to affect measures of genotoxic potential of test chemicals. Others have applied differential labelling of chromatin of dead and dying cells with ethidium monoazide when scoring MN by flow cytometry (Avlasevich et al. 2006). Shed or shedding apoptotic intestinal cells have been identified using immunohistochemical techniques to enumerate early apoptotic cells expressing active caspase-3 (Bullen et al. 2006). In our model, we probed activated cleaved caspase- 3 to detect early apoptotic cells prior to DNA fragmentation and shedding. Our data indicate the expression of active caspase-3 is persistent rather than transient; fluorescent signal intensity increased with DNA fragmentation, providing an early marker of apoptosis permitting us to distinguish DNA fragment(s) stemming from apoptotic cells from genuine MN. Our analyses of background MN compared to MN induced by reference genotoxins reveal that only a small fraction of DNA fragment(s) stemming from apoptotic cells were detected in 3D EpiIntestinal ${ }^{\mathrm{TM}}$ in vitro models. In our optimized protocols, frequent and thorough rinsing of the 3D tissues with HBSS effectively removed majority of basal apoptotic cells. We are confident that measures of $\mathrm{MN}$ in the 3D EpiIntestinal ${ }^{\mathrm{TM}}$ in vitro models following the RICyt assay protocols are not confounded by the presence of basal apoptosis.

In contrast to 3D tissue in vivo, the delivery of nutrients, growth factors and test reagents in vitro occurs via homogeneous culture media, such that all cells in 2D monolayer culture assays are exposed to identical conditions. The 2D cell culture method does not mimic the in vivo microenvironment of homeostatic tissue. Hence, cell populations cultivated in 2D tend to be synchronized, without a native extracellular matrix, and exist in a chronic state of proliferation (Tibbitt and Anseth 2009; Huh et al. 2011). In contrast, when cultivated in 3D culture systems, each cell interacts with a native-like pericellular tissue matrix, that serves to support cell differentiation and non-homogenous, stratified, $3 \mathrm{D}$ organisation. When grown in appropriate 3D organisation, cell morphology and physiology more closely recapitulate native tissue in vivo. It is, therefore, unsurprising that 3D cultures comprise unsynchronized cells in all stages of the cell cycle, including quiescence (G0), growth (G1/G2), proliferation (S), division (M), and also cell death (e.g. apoptosis, necrosis). Heterogeneity is characteristic of in vivo environments. We suggest that $3 \mathrm{D}$ tissue in vitro models represent a more authentic tissue technology platform for the assessment of genotoxicants.

Since we concluded that applying classical Cyt-B method to block cytokinesis was not viable in the 3D EpiIntestinal $^{\mathrm{TM}}$ in vitro model, we adopted methodologies and concepts from the buccal micronucleus cytome assay, BMCyt. Originally described by Thomas et al. (2009), the BMCyt protocol assays the frequency of all cell types (binucleated cells, basal stem cells, atypical cells (condensed chromatin, karyorrhectic, pyknotic and karyolytic), rather than $\mathrm{MN}$ and nuclear buds, within in a minimum population of 1000 cells. The prevalence of $\mathrm{MN}$ and nuclear buds is scored from a minimum population of 2000 differentiated cells (Thomas et al. 2009). We modified this approach for our analysis of 3D EpiIntestinal ${ }^{\mathrm{TM}}$ model tissues, scoring basal, transitional and terminally differentiated cells as distinct populations; we subsequently pooled the three populations and reclassified them simply as 'mononucleated cells'. For ease of scoring, MN and nuclear anomalies evident in each sample were scored at the same time we scored the three cell subpopulations. A minimum of 3000 cells were scored per test condition (i.e. the final $\mathrm{MN}$ data were tabulated from three independent experiments. Each experiment consisted 
of a single microtissue per test dose. A thousand cells were scored per microtissue.).

When challenged with benzo(a)pyrene without the use of exogenous metabolic activator (rat liver S9) the 3D EpiIntestinal $^{\mathrm{TM}}$ in vitro model is at least partially metabolically competent (Ayehunie et al. 2018). We demonstrate that the modified BMCyt protocol, that we call RICyt assay, produces more realistic and relevant genotoxicity responses in 3D EpiIntestinal ${ }^{\mathrm{TM}}$ that are comparable with rodent gut micronucleus assay (Coffing et al. 2011) and reconstructed skin MN assay (Hu et al. 2009; Aardema et al. 2010) at similar doses. The RICyt assay demonstrated that the nongenotoxic cytotoxin, phenformin $\mathrm{HCl}$, is inactive, whilst known reference genotoxicants are positive. These findings indicate that the RICyt assay protocol is a promising genotoxicity test platform.

At this stage, we have presented a proof-of-concept study of the RICyt assay as promising predictive tool in hazard identification of genotoxic materials. Although further work is needed to increase the validation of the assay, we show good correlation of our system with in vitro $3 \mathrm{D}$ and in vivo results (published by other groups) for the test materials. It is important to note, that $3 \mathrm{D}$ EpiIntestinal ${ }^{\mathrm{TM}}$ in vitro model is not fully identical to human native intestine: it lacks mucus secretion, commensal microbiota and peristalsis/ fluid shear. Future work will investigate how to address these factors and assess their impact on the assay sensitivity and specificity. We are also currently validating the 3D EpiIntestinal $^{\mathrm{TM}}$ in vitro model with a Comet assay protocol to detect additional genotoxicty endpoints to complement the RICyt assay protocol and enhance the utility of the model for genotoxicity testing. The MN-cytome scoring protocol described herein is a manual process and, as such, is timeconsuming and requires trained and experienced users to assure the accuracy of the resulting data. Consequently, we have initiated collaborations to develop and validate automated scoring platforms to be used with the assay that we hope will aid progression towards high-content and/or highthroughput screening of multiple endpoints from samples subjected to the RICyt assay protocol. We believe our RICyt assay system offers a viable model bridging the gap between $2 \mathrm{D}$ cell and in vivo test systems and is well positioned to become a validated tool for assessing the safety of ingested materials, especially complex and novel food ingredients and technologies.

Acknowledgements This study is supported by Industry Alignment Fund (Pre-Positioning) (IAF-PP-H18/01/a0/G14), Biomedical Research Council (BMRC, A*STAR). BPC Smith was also supported by a National Research Foundation Singapore Whitespace Grant (W20W3D0002) administered by A*STAR. We are very grateful to Graham Wright at the A*STAR microscopy platform (Agency for Science, Technology and Research) for expertise on microscopy and Dr Wang Zheng Ming (NCFS, SFA) for his contribution to the project discussions. We would like to thank Stefan Pfuhler, Procter \& Gamble, for advice on the micronuclei assay. We also thank Seyoum Ayehunie (MatTek Corporation) for expert advice regarding optimising in vitro culture condition of 3D EpiIntestinal ${ }^{\mathrm{TM}}$.

Author contributions Conceptualization: BPCS, DIL, ZMW and KWN. Investigation: LHK, COH, ML, MR, JL and CY. Data analysis: BPCS, DIL, LHK, COH, ML, MR, JL and CY. Funding acquisition: BPCS, DIL, ZMW and KWN. Project administration and supervision: BPCS and DIL. Writing — original draft: LHK. Writing—review and editing: BPCS, DIL, CY, KRC, and KWN.

\section{Declarations}

Conflict of interest The authors declare that they have no conflict of interest.

Ethics approval The manuscript does not report any clinical or patient data.

Open Access This article is licensed under a Creative Commons Attribution 4.0 International License, which permits use, sharing, adaptation, distribution and reproduction in any medium or format, as long as you give appropriate credit to the original author(s) and the source, provide a link to the Creative Commons licence, and indicate if changes were made. The images or other third party material in this article are included in the article's Creative Commons licence, unless indicated otherwise in a credit line to the material. If material is not included in the article's Creative Commons licence and your intended use is not permitted by statutory regulation or exceeds the permitted use, you will need to obtain permission directly from the copyright holder. To view a copy of this licence, visit http://creativecommons.org/licenses/by/4.0/.

\section{References}

Aardema MJ, Barnett BC, Khambatta Z, Reisinger K, Ouedraogo-Arras $\mathrm{G}$, Faquet B et al (2010) International prevalidation studies of the EpiDerm ${ }^{\mathrm{TM}}$ 3D human reconstructed skin micronucleus (RSMN) assay: transferability and reproducibility. Mutat Res Genet Toxicol Environ Mutagen 701(2):123-131

Altay G, Larrañaga E, Tosi S, Barriga FM, Batlle E, Fernández-Majada $\mathrm{V}$ et al (2019) Self-organized intestinal epithelial monolayers in crypt and villus-like domains show effective barrier function. Sci Rep 9(1):10140

Amidon GL, Lee PI, Topp EM (eds) (1999) Transport processes in pharmaceutical systems, 1st edn. CRC Press

Avlasevich SL, Bryce SM, Cairns SE, Dertinger SD (2006) In vitro micronucleus scoring by flow cytometry: differential staining of micronuclei versus apoptotic and necrotic chromatin enhances assay reliability. Environ Mol Mutagen 47(1):56-66

Ayehunie S, Landry T, Stevens Z, Armento A, Hayden P, Klausner M (2018) Human primary cell-based organotypic microtissues for modeling small intestinal drug absorption. Pharm Res 35(4):72

Belloc F, Belaud-Rotureau MA, Lavignolle V, Bascans E, BrazPereira E, Durrieu F et al (2000) Flow cytometry detection of caspase 3 activation in preapoptotic leukemic cells. Cytometry 40(2):151-160

Bergoglio V, Boyer AS, Walsh E, Naim V, Legube G, Lee MY et al (2013) DNA synthesis by Pol $\eta$ promotes fragile site stability by preventing under-replicated DNA in mitosis. J Cell Biol 201(3):395-408 
Bolognesi C, Fenech M (2019) Micronucleus cytome assays in human lymphocytes and buccal cells. Methods Mol Biol 2031:147-163

Bolognesi C, Knasmueller S, Nersesyan A, Thomas P, Fenech M (2013) The HUMNxl scoring criteria for different cell types and nuclear anomalies in the buccal micronucleus cytome assayan update and expanded photogallery. Mutat Res Rev Mutat Res 753(2):100-113

Bolognesi C, Roggieri P, Ropolo M, Thomas P, Hor M, Fenech M et al (2015) Buccal micronucleus cytome assay: results of an intra- and inter-laboratory scoring comparison. Mutagenesis 30(4):545-555

Bolognesi C, Knasmueller S, Nersesyan A, Roggieri P, Ceppi M, Bruzzone $\mathrm{M}$ et al (2017) Inter-laboratory consistency and variability in the buccal micronucleus cytome assay depends on biomarker scored and laboratory experience: results from the HUMNxl international inter-laboratory scoring exercise. Mutagenesis 32(2):257-266

Borgstrom B, Dahlqvist A, Lundh G, Sjovall J (1957) Studies of intestinal digestion and absorption in the human. J Clin Invest 36(10):1521-1536

Bullen TF, Forrest S, Campbell F, Dodson AR, Hershman MJ, Pritchard DM et al (2006) Characterization of epithelial cell shedding from human small intestine. Lab Investig 86(10):1052-1063

Byun T, Karimi M, Marsh JL, Milovanovic T, Lin F, Holcombe RF (2005) Expression of secreted Wnt antagonists in gastrointestinal tissues: potential role in stem cell homeostasis. J Clin Pathol 58(5):515-519

Carter SB (1967) Effects of cytochalasins on mammalian cells. Nature 213(5073):261-264

Clevers H, Batlle E (2013) SnapShot: the intestinal crypt. Cell 152(5):1198.e2

Coffing S, Engel M, Dickinson D, Thiffeault C, Spellman R, Shutsky $T$ et al (2011) The rat gut micronucleus assay: a good choice for alternative in vivo genetic toxicology testing strategies. Environ Mol Mutagen 52(4):269-279

Cox JA, Fellows MD, Hashizume T, White PA (2016) The utility of metabolic activation mixtures containing human hepatic postmitochondrial supernatant (S9) for in vitro genetic toxicity assessment. Mutagenesis 31(2):117-130

Creamer B, Shorter RG, Bamforth J (1961) The turnover and shedding of epithelial cells I The turnover in the gastro-intestinal tract. Gut 2:110-118

Dahl EL, Curren R, Barnett BC, Khambatta Z, Reisinger K, Ouedraogo G et al (2011) The reconstructed skin micronucleus assay (RSMN) in EpiDerm ${ }^{\mathrm{TM}}$ : detailed protocol and harmonized scoring atlas. Mutat Res Genet Toxicol Environ Mutagen 720(1):42-52

de Boer A, Krul L, Fehr M, Geurts L, Kramer N, Tabernero Urbieta M et al (2020) Animal-free strategies in food safety and nutrition: what are we waiting for? Part I: food safety. Trends Food Sci Technol 106:469-484

Di Baldassarre A, Secchiero P, Grilli A, Celeghini C, Falcieri E, Zauli G (2000) Morphological features of apoptosis in hematopoietic cells belonging to the T-lymphoid and myeloid lineages. Cell Mol Biol (noisy-Le-Grand) 46(1):153-161

Doak SH, Griffiths SM, Manshian B, Singh N, Williams PM, Brown AP et al (2009) Confounding experimental considerations in nanogenotoxicology. Mutagenesis 24(4):285-293

Doak SH, Manshian B, Jenkins GJS, Singh N (2012) In vitro genotoxicity testing strategy for nanomaterials and the adaptation of current OECD guidelines. Mutat Res 745(1-2):104-111

Doering J, Begue B, Lentze MJ, Rieux-Laucat F, Goulet O, Schmitz J et al (2004) Induction of T lymphocyte apoptosis by sulphasalazine in patients with Crohn's disease. Gut 53(11):1632-1638

Dvorakova M, Kejlova K, Kašparová L, Daniel K, Dagmar J (2015) Safety evaluation of nanosilver using reconstructed human GIT tissues. World Congress and Expo on Nanotechnology and Materials Science, Dubai, UAE
Fenech M (2000) The in vitro micronucleus technique. Mutat Res 455(1-2):81-95

Fenech M (2002) Chromosomal biomarkers of genomic instability relevant to cancer. Drug Discov Today 7(22):1128-1137

Fenech M (2007) Cytokinesis-block micronucleus cytome assay. Nat Protoc 2(5): 1084-1104

Fenech M, Morley A (1985a) Solutions to the kinetic problem in the micronucleus assay. Cytobios 43(172-173):233-246

Fenech M, Morley AA (1985b) Measurement of micronuclei in lymphocytes. Mutat Res 147(1-2):29-36

Fenech M, Morley AA (1986) Cytokinesis-block micronucleus method in human lymphocytes: effect of in vivo ageing and low dose X-irradiation. Mutat Res 161(2):193-198

Fenech MF, Dunaiski V, Osborne Y, Morley AA (1991) The cytokinesis-block micronucleus assay as a biological dosimeter in spleen and peripheral blood lymphocytes of the mouse following acute whole-body irradiation. Mutat Res 263(2):119-126

Fenech M, Chang WP, Kirsch-Volders M, Holland N, Bonassi S, Zeiger E et al (2003) HUMN project: detailed description of the scoring criteria for the cytokinesis-block micronucleus assay using isolated human lymphocyte cultures. Mutat Res 534(1-2):65-75

Fenech M, Holland N, Zeiger E, Chang WP, Burgaz S, Thomas P et al (2011) The HUMN and HUMNxL international collaboration projects on human micronucleus assays in lymphocytes and buccal cells-past, present and future. Mutagenesis 26(1):239-245

Gao C, Wang AY (2009) Significance of increased apoptosis and Bax expression in human small intestinal adenocarcinoma. J Histochem Cytochem 57(12):1139-1148

Gregorieff A, Pinto D, Begthel H, Destrée O, Kielman M, Clevers H (2005) Expression pattern of Wnt signaling components in the adult intestine. Gastroenterology 129(2):626-638

Günther C, Neumann H, Neurath MF, Becker C (2013) Apoptosis, necrosis and necroptosis: cell death regulation in the intestinal epithelium. Gut 62(7):1062-1071

Hamada S, Ohyama W, Takashima R, Shimada K, Matsumoto K, Kawakami S et al (2015) Evaluation of the repeated-dose liver and gastrointestinal tract micronucleus assays with 22 chemicals using young adult rats: summary of the collaborative study by the Collaborative Study Group for the Micronucleus Test (CSGMT)/ The Japanese Environmental Mutagen Society (JEMS)—Mammalian Mutagenicity Study Group (MMS). Mutat Res Genet Toxicol Environ Mutagen 780-781:2-17

Hardy A, Benford D, Halldorsson T, Jeger MJ, Knutsen HK, More S et al (2018) Guidance on risk assessment of the application of nanoscience and nanotechnologies in the food and feed chain: part 1, human and animal health. EFSA J 16(7):e05327

Helander HF, Fändriks L (2014) Surface area of the digestive tractrevisited. Scand J Gastroenterol 49(6):681-689

Henson TE, Navratilova J, Tennant AH, Bradham KD, Rogers KR, Hughes MF (2019) intestinal toxicity of copper oxide nanoparticles in rat and human cell models. Nanotoxicology 13(6):795-811

Hidalgo IJ, Raub TJ, Borchardt RT (1989) Characterization of the human colon carcinoma cell line (Caco-2) as a model system for intestinal epithelial permeability. Gastroenterology 96(3):736-749

Hilgers AR, Conradi RA, Burton PS (1990) Caco-2 cell monolayers as a model for drug transport across the intestinal mucosa. Pharm Res 7(9):902-910

Holland N, Bolognesi C, Kirsch-Volders M, Bonassi S, Zeiger E, Knasmueller S et al (2008) The micronucleus assay in human buccal cells as a tool for biomonitoring DNA damage: the HUMN project perspective on current status and knowledge gaps. Mutat Res 659(1-2):93-108

Hu T, Kaluzhny Y, Mun GC, Barnett B, Karetsky V, Wilt N et al (2009) Intralaboratory and interlaboratory evaluation of the EpiDerm ${ }^{\mathrm{TM}}$ 3D human reconstructed skin micronucleus (RSMN) assay. Mutat Res Genet Toxicol Environ Mutagen 673(2):100-108 
Huh D, Hamilton GA, Ingber DE (2011) From 3D cell culture to organs-on-chips. Trends Cell Biol 21(12):745-754

Jayakumar D, Kasturi KK (2020) Micronucleus and its significance in effusion fluids. J Cytol 37(1):58-61

Kejlová K, Dvořáková M, Vavrouš A, Ševčík V, Kand'árová H, Letašiová $S$ et al (2019) Toxicity of food contact paper evaluated by combined biological and chemical methods. Toxicol in Vitro 59:26-34

Kejlova K, Vavrouš A, Dvorakova M, Sosnovcová J, Jirova D (2015) Health safety of food contact paper evaluated by in vitro toxicological methods. EUSAAT 2015 - 16th annual Congress of EUSAAT AND LINZ 2015 - 19th European Congress on Alternatives to Animal Testing. ALTEX Proceedings, vol 4, no. 2. Johannes Kepler University (JKU) Linz, Austria

Kirkland D, Uno Y, Luijten M, Beevers C, van Benthem J, Burlinson $B$ et al (2019) In vivo genotoxicity testing strategies: Report from the 7th International workshop on genotoxicity testing (IWGT). Mutat Res Genet Toxicol Environ Mutagen 847:403035

Kirsch-Volders M, Fenech M (2001) Inclusion of micronuclei in nondivided mononuclear lymphocytes and necrosis/apoptosis may provide a more comprehensive cytokinesis block micronucleus assay for biomonitoring purposes. Mutagenesis 16(1):51-58

Le Beau MM, Rassool FV, Neilly ME, Espinosa R, Glover TW, Smith DI et al (1998) Replication of a common fragile site, FRA3B, occurs late in $\mathrm{S}$ phase and is delayed further upon induction: implications for the mechanism of fragile site induction. Hum Mol Genet 7(4):755-761

Llewellyn SV, Conway GE, Shah UK, Evans SJ, Jenkins GJS, Clift MJD, Doak SH (2020) Advanced 3D liver models for in vitro genotoxicity testing following long-term nanomaterial exposure. J vis Exp 5(160):e61141-e61150

Lukamowicz M, Kirsch-Volders M, Suter W, Elhajouji A (2011) In vitro primary human lymphocyte flow cytometry based micronucleus assay: simultaneous assessment of cell proliferation, apoptosis and MN frequency. Mutagenesis 26(6):763-770

Luzhna L, Kathiria P, Kovalchuk O (2013) Micronuclei in genotoxicity assessment: from genetics to epigenetics and beyond. Front Genet 4:131

Martus HJ, Hayashi M, Honma M, Kasper P, Gollapudi B, Mueller L et al (2015) Summary of major conclusions from the 6th international workshop on genotoxicity testing (IWGT), Foz do Iguaçu, Brazil. Mutat Res Genet Toxicol Environ Mutagen 783:1-5

Noah TK, Donahue B, Shroyer NF (2011) Intestinal development and differentiation. Exp Cell Res 317(19):2702-2710

OECD (2016) Test No. 474: Mammalian Erythrocyte Micronucleus Test, OECD Guidelines for the Testing of Chemicals, Section 4, OECD Publishing, Paris. https://doi.org/10.1787/9789264264 762-en

OECD (2016) Test No. 487: In Vitro Mammalian Cell Micronucleus Test, OECD Guidelines for the Testing of Chemicals, Section 4, OECD Publishing, Paris. https://doi.org/10.1787/9789264264 861-en

OECD (2019), Test No. 431: In vitro skin corrosion: reconstructed human epidermis (RHE) test method, OECD Guidelines for the Testing of Chemicals, Section 4, OECD Publishing, Paris. https:// doi.org/10.1787/9789264264618-en

Park JH, Kotani T, Konno T, Setiawan J, Kitamura Y, Imada S et al (2016) Promotion of intestinal epithelial cell turnover by commensal bacteria: role of short-chain fatty acids. PLoS ONE 11(5): $\mathrm{e} 0156334$

Peters MF, Landry T, Pin C, Maratea K, Dick C, Wagoner MP et al (2019) Human 3D gastrointestinal microtissue barrier function as a predictor of drug-induced diarrhea. Toxicol Sci 168(1):3-17

Pind’áková L, Kašpárková V, Kejlová K, Dvořáková M, Krsek D, Jírová $\mathrm{D}$ et al (2017) Behaviour of silver nanoparticles in simulated saliva and gastrointestinal fluids. Int J Pharm 527(1-2):12-20
Pridgeon CS, Schlott C, Wong MW, Heringa MB, Heckel T, Leedale $\mathrm{J}$ et al (2018) Innovative organotypic in vitro models for safety assessment: aligning with regulatory requirements and understanding models of the heart, skin, and liver as paradigms. Arch Toxicol 92(2):557-569

Schmid W (1975) The micronucleus test. Mutat Res 31(1):9-15

Simon-Assmann P, Turck N, Sidhoum-Jenny M, Gradwohl G, Kedinger M (2007) In vitro models of intestinal epithelial cell differentiation. Cell Biol Toxicol 23(4):241-256

Sommer S, Buraczewska I, Kruszewski M (2020) Micronucleus Assay: the state of art, and future directions. Int J Mol Sci 21(4):1534-1552

Srinivasan B, Kolli AR, Esch MB, Abaci HE, Shuler ML, Hickman JJ (2015) TEER measurement techniques for in vitro barrier model systems. J Lab Autom 20(2):107-126

Strober W (2015) Trypan blue exclusion test of cell viability. Curr Protoc Immunol 111:A3.B

Takenaka T, Harada N, Kuze J, Chiba M, Iwao T, Matsunaga T (2016) Application of a human intestinal epithelial cell monolayer to the prediction of oral drug absorption in humans as a superior alternative to the Caco-2 cell monolayer. J Pharm Sci 105(2):915-924

Tan HY, Trier S, Rahbek UL, Dufva M, Kutter JP, Andresen TL (2018) A multi-chamber microfluidic intestinal barrier model using Caco-2 cells for drug transport studies. PLoS ONE 13(5): $\mathrm{e} 0197101$

Thomas P, Fenech M (2011) Buccal micronucleus cytome assay. In: Didenko VV (ed) DNA damage detection in situ, ex vivo, and in vivo: methods and protocols. Humana Press, Totowa, pp 235-248

Thomas P, Holland N, Bolognesi C, Kirsch-Volders M, Bonassi S, Zeiger E et al (2009) Buccal micronucleus cytome assay. Nat Protoc 4(6):825-837

Tibbitt MW, Anseth KS (2009) Hydrogels as extracellular matrix mimics for 3D cell culture. Biotechnol Bioeng 103(4):655-663

Tolbert PE, Shy CM, Allen JW (1992) Micronuclei and other nuclear anomalies in buccal smears: methods development. Mutat Res 271(1):69-77

Umar S (2010) Intestinal stem cells. Curr Gastroenterol Rep 12(5):340-348

Uno Y, Morita T, Luijten M, Beevers C, Hamada S, Itoh S et al (2015) Recommended protocols for the liver micronucleus test: report of the IWGT working group. Mutat Res Genet Toxicol Environ Mutagen 783:13-18

Vaidya B, Shukla SK, Kolluru S, Huen M, Mulla N, Mehra N et al (2019) Nintedanib-cyclodextrin complex to improve bio-activity and intestinal permeability. Carbohydr Polym 204:68-77

Van Bossuyt M, Van Hoeck E, Vanhaecke T, Rogiers V, Mertens B (2019) Prioritizing substances of genotoxic concern for in-depth safety evaluation using non-animal approaches: the example of food contact materials. Altex 36(2):215-230

Watson AJ (2004) Apoptosis and colorectal cancer. Gut 53(11):1701-1709

Widrow RJ, Hansen RS, Kawame H, Gartler SM, Laird CD (1998) Very late DNA replication in the human cell cycle. Proc Natl Acad Sci USA 95(19):11246-11250

Williams JM, Duckworth CA, Burkitt MD, Watson AJ, Campbell BJ, Pritchard DM (2015) Epithelial cell shedding and barrier function: a matter of life and death at the small intestinal villus tip. Vet Pathol 52(3):445-455

Xavier M, Parente IA, Rodrigues PM, Cerqueira MA, Pastrana L, Gonçalves C (2021) Safety and fate of nanomaterials in food: the role of in vitro tests. Trends Food Sci Technol 109:593-607

Zhang J, Wang X, Cui W, Wang W, Zhang H, Liu L et al (2013) Visualization of caspase-3-like activity in cells using a genetically encoded fluorescent biosensor activated by protein cleavage. Nat Commun 4:2157 
Zhang Y, Shu H, Hu J, Zhang M, Wu J, Liu K et al (2016) Binding affinity, cellular uptake, and subsequent intracellular trafficking of the nano-gene vector P123-PEI-R13. J Nanomater 2016:7064246
Publisher's Note Springer Nature remains neutral with regard to jurisdictional claims in published maps and institutional affiliations.

\section{Authors and Affiliations}

\section{Hui Kheng Lim ${ }^{1,2,3}$ (1) Christopher Owen Hughes ${ }^{1,2} \cdot$ Michelle Jing Sin Lim ${ }^{1,4} \cdot$ Jia'En Jasmine Li $^{5} \cdot$ Moumita Rakshit $^{6}$. Calvin $\mathrm{Yeo}^{5} \cdot$ Kern Rei Chng ${ }^{5}$. Angela $\mathrm{Li}^{5} \cdot$ Joanne Sheot Harn Chan ${ }^{5} \cdot \mathrm{Kee}$ Woei $\mathrm{Ng}^{6,7,8} \cdot$ David lan Leavesley ${ }^{1,2}$. Benjamin Paul Chapman Smith ${ }^{1,3,4}$}

1 Innovations in Food and Chemical Safety (IFCS)

Programme, Agency for Science, Technology and Research, Singapore, Singapore

2 Skin Research Institute of Singapore (SRIS), Agency for Science, Technology and Research, Singapore, Singapore

3 Future Ready Food Safety Hub (a Joint Initiative of A*STAR, SFA and NTU), Nanyang Technological University, Singapore, Singapore

4 Singapore Institute of Food and Biotechnology Innovation (SIFBI), Agency for Science, Technology and Research, Singapore, Singapore
5 National Centre for Food Science, Singapore Food Agency, Singapore, Singapore

6 School of Materials Science and Engineering, Nanyang Technological University, Singapore, Singapore

7 Environmental Chemistry and Materials Centre, Nanyang Environment and Water Research Institute, Singapore, Singapore

8 Harvard T. H. Chan School of Public Health, Harvard University, Cambridge, USA 